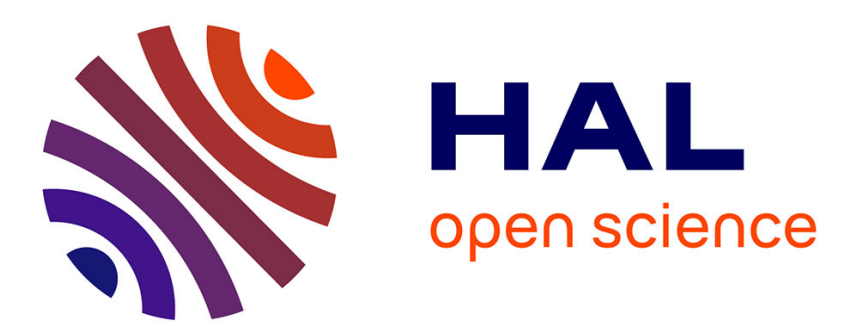

\title{
Low-cycle fatigue life of a thermal break system under climatic actions
}

Pisey Keo, Benoit Le Gac, Hugues Somja, Frank Palas

\section{To cite this version:}

Pisey Keo, Benoit Le Gac, Hugues Somja, Frank Palas. Low-cycle fatigue life of a thermal break system under climatic actions. Engineering Structures, 2018, 168, pp.525-543. 10.1016/j.engstruct.2018.04.063 . hal-01809293

\section{HAL Id: hal-01809293}

\section{https://hal-univ-rennes1.archives-ouvertes.fr/hal-01809293}

Submitted on 27 Sep 2018

HAL is a multi-disciplinary open access archive for the deposit and dissemination of scientific research documents, whether they are published or not. The documents may come from teaching and research institutions in France or abroad, or from public or private research centers.
L'archive ouverte pluridisciplinaire HAL, est destinée au dépôt et à la diffusion de documents scientifiques de niveau recherche, publiés ou non, émanant des établissements d'enseignement et de recherche français ou étrangers, des laboratoires publics ou privés. 


\title{
Low-cycle fatigue life of a thermal break system under climatic actions
}

\author{
Pisey Keo ${ }^{\mathrm{a}}$, Benoit Le Gac ${ }^{\mathrm{a}, \mathrm{b}, *}$, Hugues Somja ${ }^{\mathrm{a}}$, Frank Palas ${ }^{\mathrm{b}}$ \\ ${ }^{a}$ Université Européenne de Bretagne - INSA de Rennes, LGCGM/Structural Engineering Research Group, 20 \\ avenue des Buttes de Coësmes, CS 70839, F-35708 Rennes Cedex 7, France \\ ${ }^{b}$ INGENOVA, Civil Engineering Office, 5 Rue Louis Jacques Daguerre, 35136 Saint-Jacques-de-la-Lande, France
}

\begin{abstract}
External insulation in the buildings is more widely used in Northern and Continental Europe than internal insulation. This technique leads to thermal bridges at the building facade that has projecting elements like balconies. In that case, to meet the thermal requirements of actual standards, the continuity of the insulation at the interfaces by using thermal break systems (TBS) is needed. These systems are usually made of a box containing the insulation material, and a minimalist structural system able to transmit the shear force and the bending moment from the balcony to the wall. In most cases, structural elements used in TBS are made of stainless steel, as it is less heat-conducting than normal steel. A specific TBS which is composed of shear keys and steel profiles to ensure the force transfer between the balcony and the wall, and which will be used for external insulation in the buildings is focused in this paper. Particularly, the TBS submitted to important horizontal cyclic shear deformations, provoked by the variations of the dimensions of the balconies due to climatic effects is considered. The objective of the study presented in this paper is to show that significant yielding under these actions can be accepted during the service life of the building. Firstly, experimental cyclic loading tests are performed in order to characterize the behaviour of the TBS, as well as its fatigue strength. Then, the loading due to climatic effects is defined on the basis of the database of the ECA\&D, the European Climate Assessment and Dataset. Finally, the fatigue resistance of the system is verified. It is shown that the developed TBS can resist to fatigue loading for a large length of balcony, even though it exhibits significant yielding during service life.
\end{abstract}

Keywords: Thermal break system, thermal bridge, low-cycle fatigue, thermal loads, SUNE, stainless steel. 


\section{Introduction}

The level of energy-performance requirements in buildings has substantially increased over the last twenty years. It is imposed by new thermal regulations to reduce energy consumption and greenhouse gas emissions in buildings. As the thickness and the efficiency of the insulation of the walls increase, the energy lost in the building is now mostly due to the discontinuity of the insulation, where so called thermal bridges are created. These thermal bridges induce moreover a local condensation of water that can cause a deterioration of the internal coating of the building and even a degradation of the indoor air quality due to the development of decay. As a consequence, thermal bridges must be reduced by the use of appropriate solutions like thermal break systems (TBS), see Fig. 1a.

In the specific case of buildings with an external insulation, thermal bridges develop at locations where the building facade has projecting element such as balconies. Usual TBS are made of a box containing the insulation material, and a minimalist structural system able to transmit the shear force and the bending moment from the balcony to the wall. In most cases, those structural elements are made of stainless steel, which is less heat-conducting than normal steel.

The first structural systems of the TBS were made of longitudinal and diagonal rebars to equilibrate the bending moment and the shear force, respectively (Fig. 1b). However, it was limited for both structural and thermal concerns. For that reason, several attempts have been made to find better solutions, for example [1-3].

The structural role of the TBS is not only to resist vertical forces, wind or even seismic actions, but also to absorb the relative displacements induced by the thermal expansion of the balcony. This critical point is discussed in the specific case of a TBS called SUNE. SUNE is an assembly of different components consisting of tensile rebars, welded to 2 transversal rebars on each side for a better anchorage, U-shaped steel sections, and special shear keys. The tensile rebars and the U-shaped steel sections are used to balance the tension and compression forces due to bending while the shear key is used to resist the shear force (Fig. 2). The web of the $\mathrm{U}$ member presents longitudinal slots at each end in order to provide some horizontal flexibility. On the lintel side, it relies on an end plate with a $U$ section, with flanges embedded in the concrete. On the balcony

\footnotetext{
${ }^{*}$ Corresponding author.

Email address: benoit.le-gac@insa-rennes.fr (Benoit Le Gac)
} 


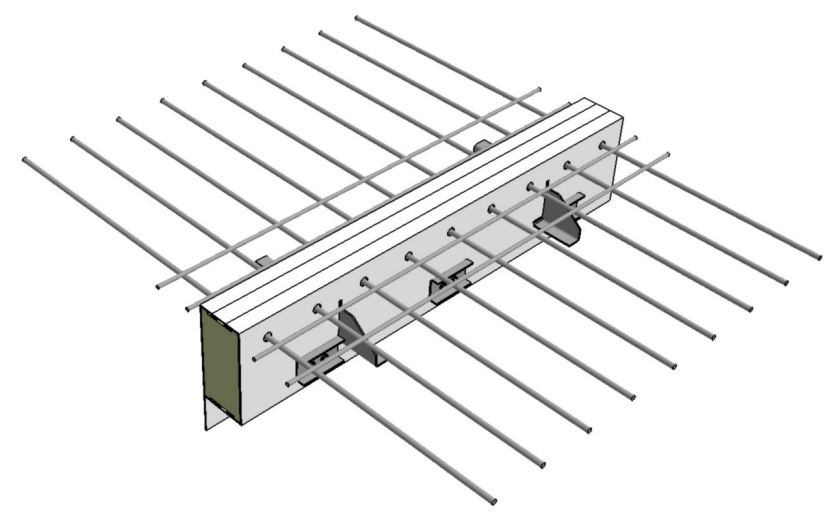

(a)

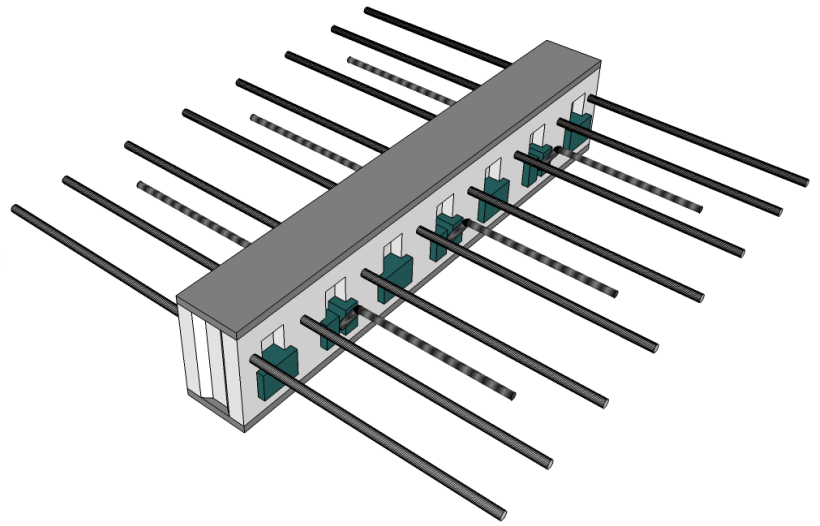

(b)

Figure 1: (a) General view of thermal break system seen from balcony side. (b) Thermal break system made of rebars.

side, a rectangular end plate is welded on the $\mathrm{U}$ member. This end plate is connected by two screws to a U-shaped end plate embedded in the concrete in the same way as on the other side. Mechanical performances of the SUNE under vertical loads are presented in [4. To contribute to thermal performance of the TBS, duplex stainless steels with yield strengths greater than 600 $\mathrm{MPa}$ and $550 \mathrm{MPa}$ are used for the rebars and the steel profiles, respectively. A mineral wool with a thermal conductivity lesser than $0.038 \mathrm{~W} /(\mathrm{m} \mathrm{K})$ is used as insulation material in the 100-mm thick insulation box. The use of those materials leads to a good thermal performance with linear thermal transmittance values below $0.27 \mathrm{~W} /(\mathrm{m} \mathrm{K})$.

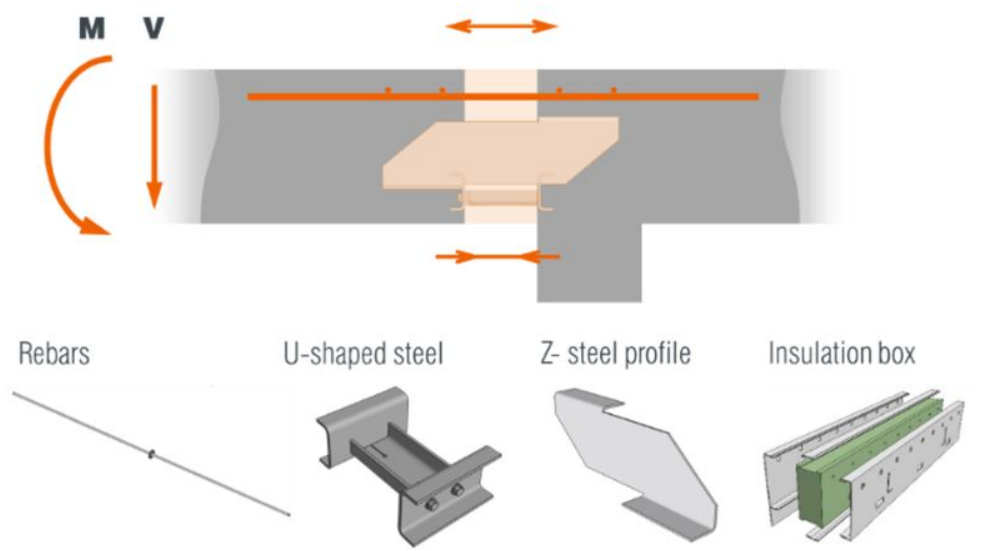

Figure 2: Decomposition of SUNE.

Being located outside the building thermal envelope, the balcony suffers climatic hazards and 
is caused to expand or shorten following climatic conditions (outside temperature, solar radiation, etc.). The thermal break is placed in line with the insulation and thus ensures the connection between the outside balcony and the inner floor slab. The latter is located inside the building envelope; consequently it only undergoes low changes in temperature. The thermal break is therefore subjected to shearing induced by the horizontal deformation of the balcony as a function of the outside-building temperature variations. For that reason, the components of TBS must be designed to be able to sustain such deformations. The bars and Z-profile have sufficient horizontal flexibility to deform freely under the thermal forces, but the U-shaped steel profile undergoes yielding even under frequent actions. The objective of the work presented in this paper is to prove that this yielding is acceptable and does not reduce the capabilities of the TBS during its service life. Three reasons have inspired this investigation. Firstly, the behaviour of stainless steels is far away from the hypothesis of an elastic perfectly plastic material. The plastic hardening of the stainless steel is stably progressive and there is not any brutal change in the behaviour at the beginning of the plastification. Therefore, the conventional choice of the limit of elasticity, the stress corresponding to a plastic deformation of $0.2 \%$, seems completely arbitrary. Secondly, the number of large cycles provoked by climatic actions is limited and corresponds to the order of magnitude that can be supported in a low-cycle fatigue. Lastly, the non plastification condition is not imposed in EN1993-1-1 [5].

Nonetheless, accepting yielding at service limit states (SLS) requires a verification against lowcycle fatigue, given the fact that the plastification may occur several times during the service life of the element. The fatigue design in this case does not correspond to the usual fatigue design considered in the domain of civil engineering: the stress is relatively high and the number of load cycles is low while the design standards deal with the high fatigue life with significantly high number of load cycles with small variations of stresses.

In this paper, the verification of the thermal break system SUNE against low-cycle fatigue loads is performed. To do so, cyclic loading tests of the TBS are conducted and presented here in Section 2. Its results serve to establish the cyclic force-displacement relationship, see Section 3, as well as the fatigue design curve of the system. The latter is obtained by adopting the procedure described in Annex D of EN 1990 [6] in order to determine the characteristic and design value of the model parameters. The detailed procedure is described in Section 4 . The fatigue design curve 
is then used to verify the fatigue strength of the thermal break system under the deformation of the balcony generated by the temperature variation outside the building. The latter is originally obtained from an European database and then calibrated to the maximum and minimum shade air temperature given by EN 1991-1-5. The description of the calibration is highlighted in Section 5 . Section 6 presents the verification of TBS against thermal loading which is done by determining the damage accumulation developed during the building life. Several meteorological stations as well as balcony lengths are considered in the parametric study.

\section{Low-cycle fatigue tests}

The mechanical behavior of the TBS under cyclic horizontal loads is evaluated through low-cycle fatigue tests. The description of this experimental program is presented in the following.

\subsection{Geometric description of the test}

The test setup consists of a hydraulic jack with a capacity of $1500 \mathrm{kN}$ imposing horizontal displacement, a specimen, and reaction/bracing systems. The RC slab of the specimen is retained vertically and horizontally by supporting systems (see Figs. 3 to 5), where the horizontal supports have a system of adjustment in order to perfectly restrain the test specimen. At the front of the RC slab near the balcony-slab junction, a lintel with a drop of $100 \mathrm{~mm}$ is enlarged at both sides to avoid any interaction with the physical phenomena near the critical zones of the thermal break component. The vertical supports are realised by pinned supports placed under the lintel. At the rear of the concrete slab, a top transverse bar is placed in order to prevent the specimen to uplift. Besides, to consider the gravity load at service limit states for frequent load combination, a block of concrete is suspended on the balcony.

\subsection{Test specimens}

The specimen consists of the balcony, the negative bending moment zone of the adjacent $\mathrm{RC}$ slab, and the balcony-slab connection component (TBS), see Fig. 6. Eight specimens are considered in the experimental test program as required by NF A03-403 [7] to produce the resistance fatigue 


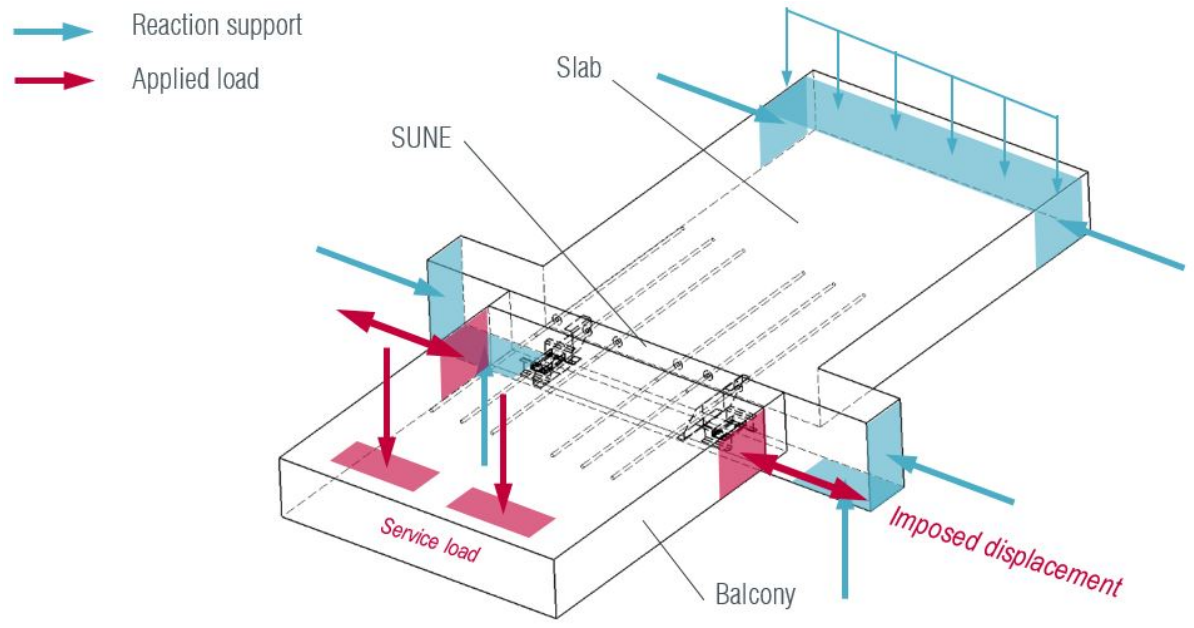

Figure 3: Action-reaction description.

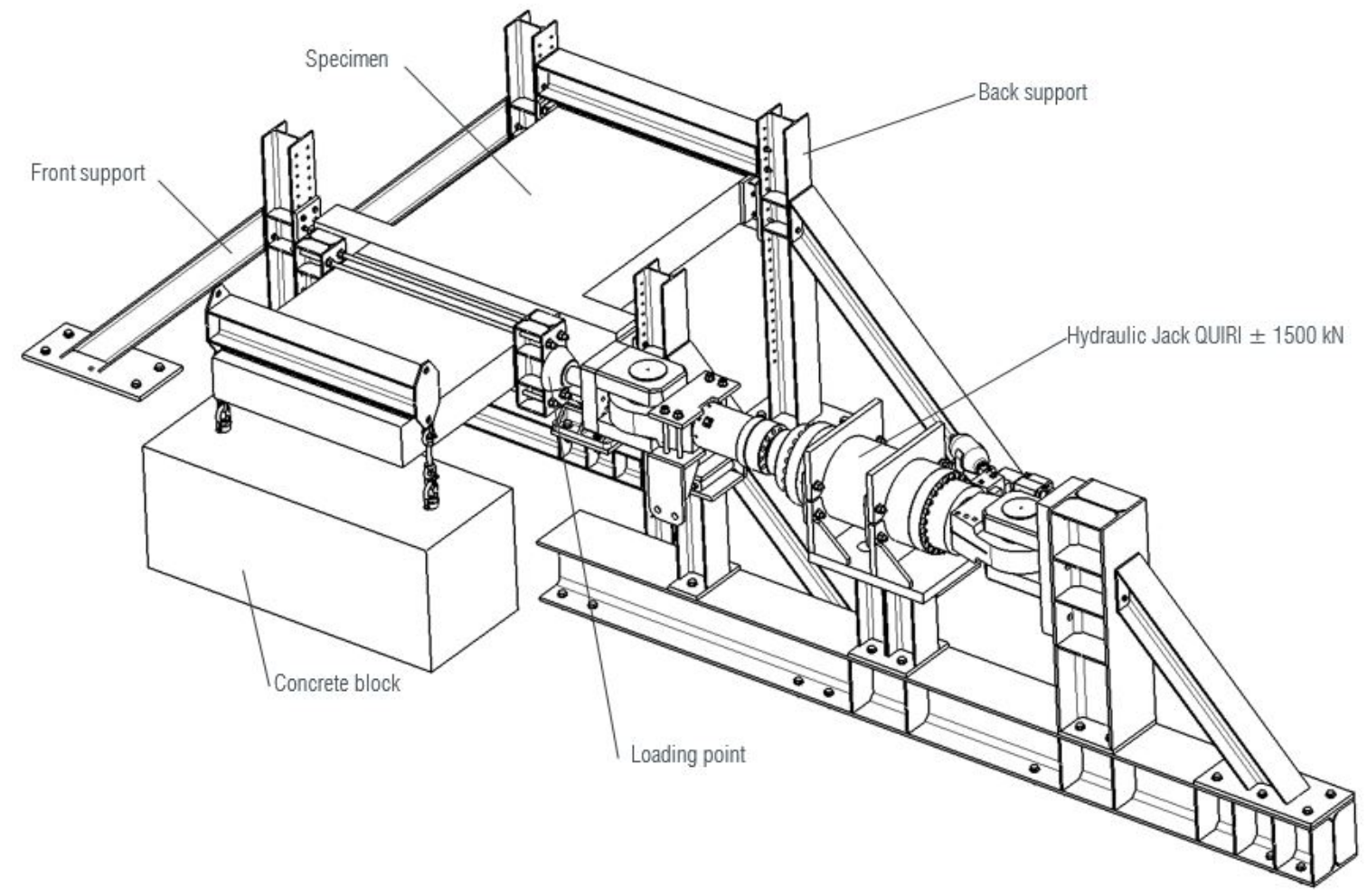

Figure 4: Overall view of the test setup.

curve, which covers at least 4 points with different numbers of cycles. The eight specimens are denoted by $\mathrm{CH} 1$ to $\mathrm{CH} 8$. 


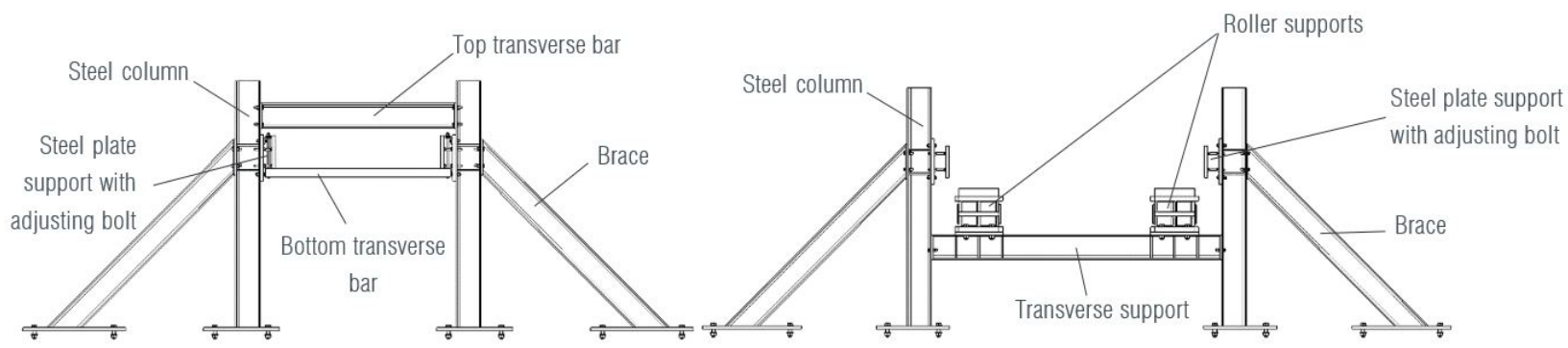

a) Back supporting system

b) Front supporting system

Figure 5: Detail of back and front supporting system.

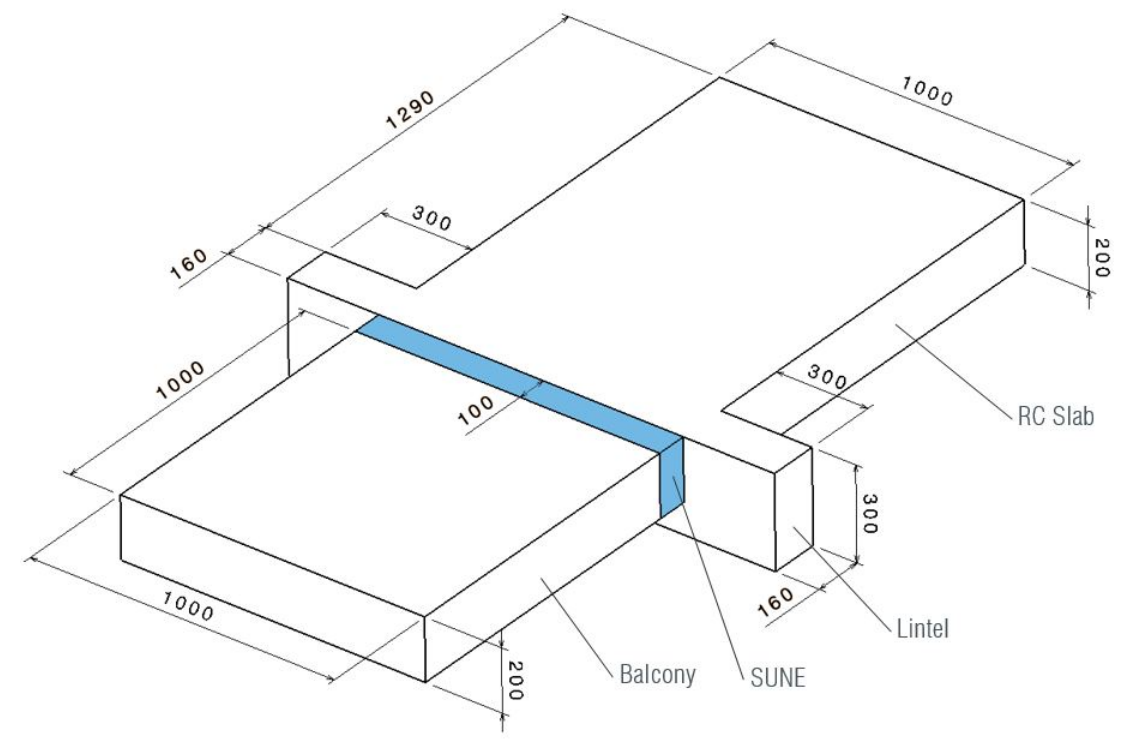

Figure 6: Dimensions of the specimen in $\mathrm{mm}$.

\subsection{Materials}

The concrete has a strength class of $\mathrm{C} 25 / 30$. The concrete characteristics at 28 days and at the day of test are determined on cylinder samples with dimensions of $11 \times 22 \mathrm{~cm}$. 3 cylindric concrete specimens are tested for each concrete age. The results of the compressive tests are listed in Table 1 .

\subsection{Loading procedure}

Cyclic tests are traditionally carried out with reference to Standard Procedures such as ECCS [8] and ATC [9] which use loading histories consisting of groups of cycles at increasing amplitudes. Such loading histories present the advantage of allowing on a single specimen a satisfactory appraisal of the cyclic performance of the component. However, they appear inadequate for the development 
Table 1: Mean material properties.

\begin{tabular}{c|cc|ccc}
\hline \multirow{2}{*}{ Specimen } & \multicolumn{2}{|c|}{28 days } & \multicolumn{3}{c}{ day of test } \\
\cline { 2 - 6 } & $f_{c m}(\mathrm{MPa})$ & Std. (MPa) & $f_{c m}(\mathrm{MPa})$ & Std. (MPa) & Age (days) \\
\hline CH1 & 36.49 & 0.14 & 34.91 & 0.51 & 39 \\
CH2 & 25.97 & 0.37 & 29.85 & 0.51 & 71 \\
CH3 & 32.46 & 0.11 & 31.94 & 0.47 & 43 \\
CH4 & 27.60 & 0.58 & 32.77 & 0.20 & 37 \\
CH5 & 27.60 & 0.58 & 28.56 & 0.52 & 50 \\
CH6 & 29.35 & 0.60 & 30.80 & 0.84 & 35 \\
CH7 & 29.35 & 0.60 & 30.13 & 0.36 & 43 \\
CH8 & 31.28 & 0.20 & 35.45 & 0.50 & 48 \\
\hline
\end{tabular}

of cumulative damage models useful not only for the seismic design of new structures but also for the assessment of safety and reliability of damaged structures and for the development of adequate repair procedures [10]. It has been recognised that repeating three cycles for each cycle amplitude and then increasing the amplitude does not provide direct information regarding the damage accumulation and strength degradation corresponding to one particular ductility demand; in fact, increasing the amplitudes corresponds to an isotropic strain hardening effect resulting in an increment of the load carrying capacity of the member, but this effect is opposite to the strength degradation due to local failure and low-cycle fatigue, which are directly connected to the cycle amplitude and the number of imposed cycles [11. With regard to the recommended testing procedure by ECCS, various researchers [10, 11] proposed a cyclic test with a constant amplitude loading history in the plastic range. This proposal is complying with NF A03-403 [7] for low-cycle fatigue tests to characterise the fatigue strength of the material.

For the present experimental tests, a sinusoidal form of the cycle is adopted, and the frequency domain is between $0.03 \mathrm{~Hz}$ and $0.1 \mathrm{~Hz}$. It is worth mentioning that at ambient temperature, the frequency has generally less effect on the results of the tests [7]. At the beginning of the loading, 10 cycle loading is applied at an amplitude of $0.24 \mathrm{~mm}$ for $\mathrm{CH} 1$ and $\mathrm{CH} 2$ specimen; then, the loading continues with increasing amplitude of $0.1 \mathrm{~mm}$ every 3 cycles up to an amplitude of $1.22 \mathrm{~mm}$. The latter amplitude is then maintained and the loading continues up to failure, see Fig. 7a. For other 
specimens (CH3 to $\mathrm{CH} 8$ ), the loading is applied similarly. A 25 cycle loading with an amplitude of $0.2 \mathrm{~mm}$ is employed at the beginning, followed by an amplitude increasing after every 3 cycles with $0.1 \mathrm{~mm}$ increment until reaching the desired testing amplitude, see Fig. 7b, Every low-cycle testing amplitude for each specimen is listed in Table 2.

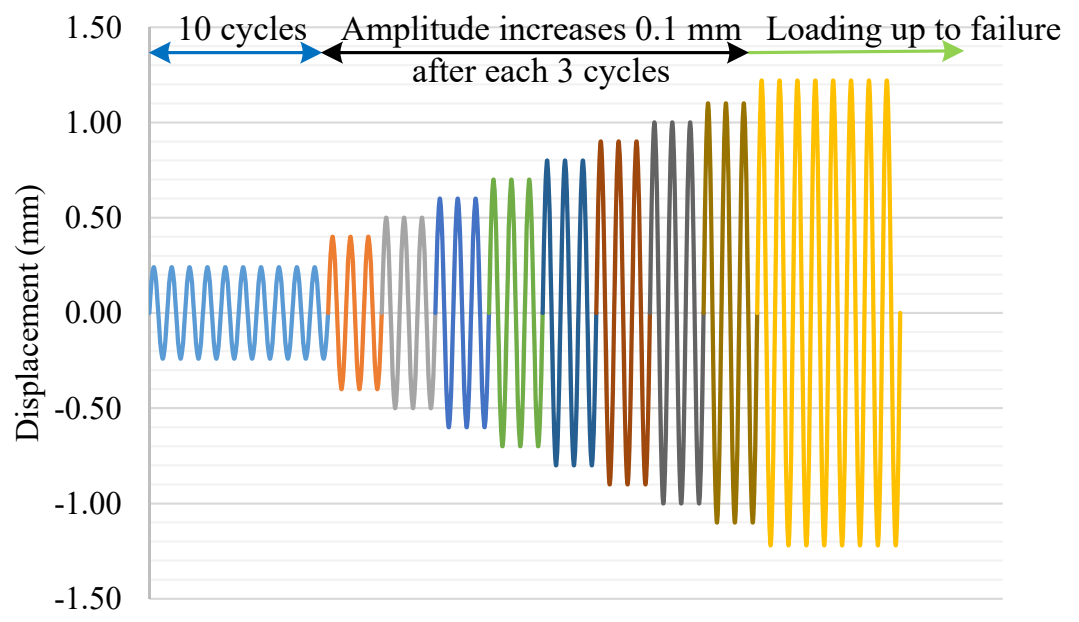

(a) $\mathrm{CH} 1-\mathrm{CH} 2$.

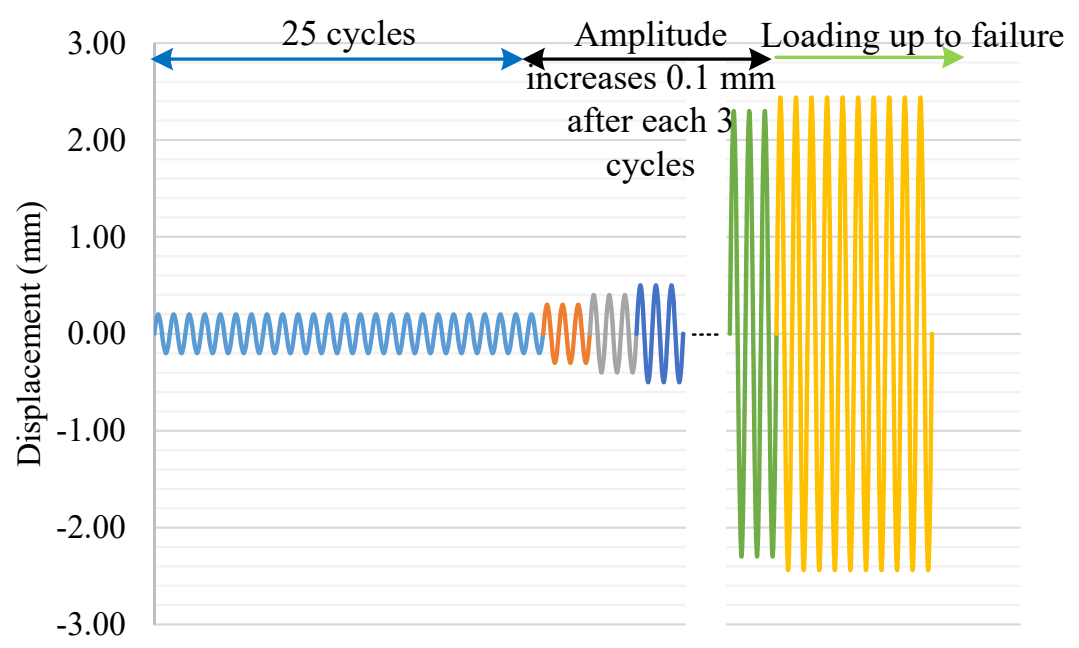

(b) $\mathrm{CH} 3$.

Figure 7: Loading history.

Table 2: Testing loading amplitude for each specimen.

\begin{tabular}{c|cccccccc}
\hline Specimen & $\mathrm{CH} 1$ & $\mathrm{CH} 2$ & $\mathrm{CH} 3$ & $\mathrm{CH} 4$ & $\mathrm{CH} 5$ & $\mathrm{CH} 6$ & $\mathrm{CH} 7$ & $\mathrm{CH} 8$ \\
\hline Amplitude $(\mathrm{mm})$ & 1.22 & 1.22 & 2.44 & 1.83 & 1.52 & 1.52 & 2.75 & 5 \\
\hline
\end{tabular}




\subsection{Instrumentation}

The force is recorded by a force sensor DELTECH $\pm 200 \mathrm{kN}$. 4 displacement sensors are installed in order to measure the vertical displacements of the whole specimen during the test (sensors $\mathrm{C} 1$ to C4) and to deduce the evolution of the rotation of the balcony with respect to the RC slab at the position of the thermal break (see Fig. 8). The measurements are carried out on the underneath of the RC slab. In order to measure the relative horizontal displacement of the balcony with respect to the RC slab, two LVDT sensors (C5 and C6) are placed on top of the test specimen (see Fig. 9). Their measurements make it possible to adapt the displacement of the hydraulic jack to the desired displacement applied to the thermal break.

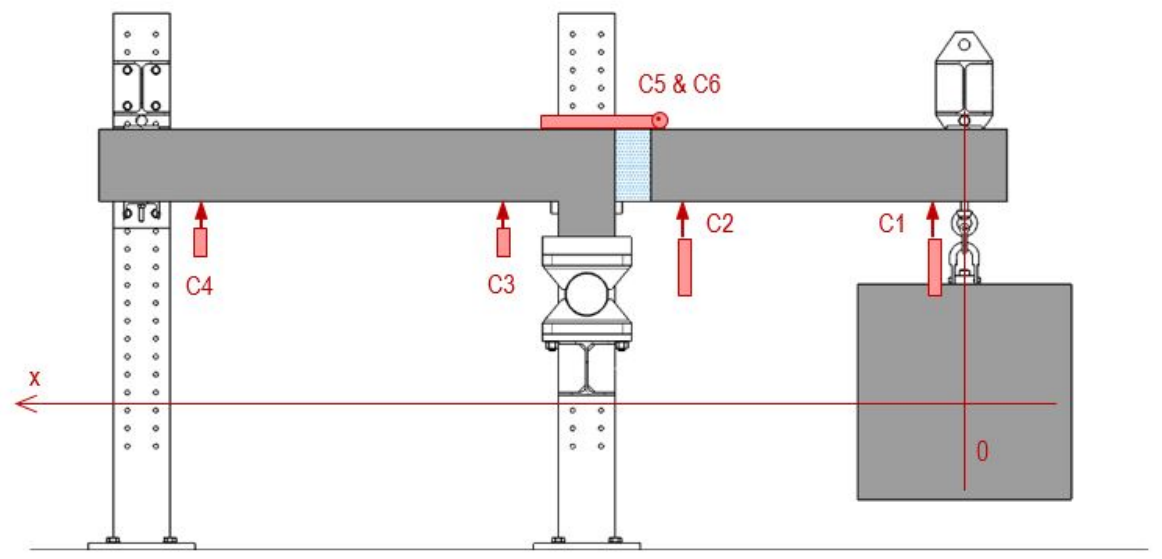

Figure 8: Side view of test instrumentation.

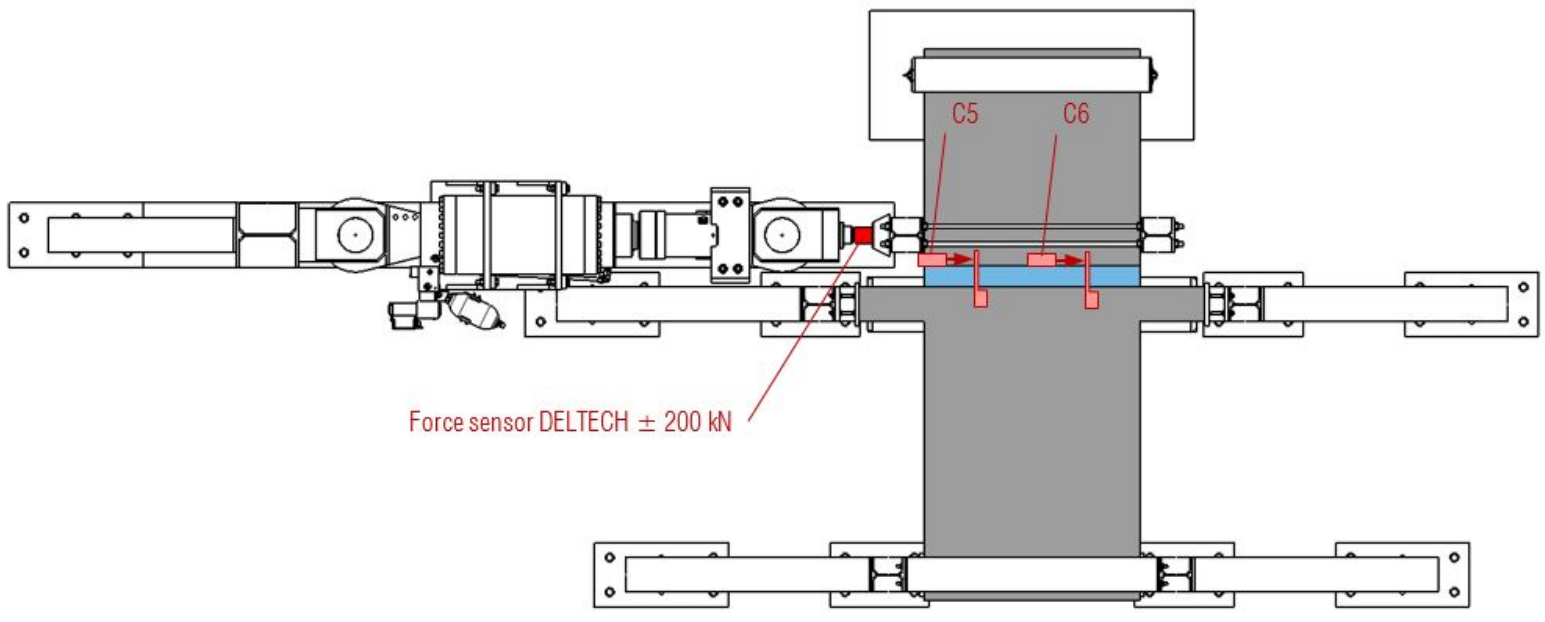

Figure 9: Top view of test instrumentation. 


\subsection{Failure criterion}

There are various methods to determine a failure criterion in fatigue. It is most commonly associated with a test end criterion other than that of the total failure of the specimen. This may depend on the interpretation of the results of the fatigue test and the nature of the device tested. Most proposed failure criteria are based on the appearance, the presence or the worsening of an observed phenomenon or recorded data, indicating extensive damage or a closely specimen break. According to NF A03-403 [7] related to the testing of the resistance of metallic material in low-cycle fatigue, the conventional number of cycles to failure can be defined as the number of cycles corresponding to:

- the total failure of the test: separation into two distinct parts,

- a decrease of a certain percentage of the maximum tensile stress in relation to a given level thereof during the test,

- a decrease of a certain percentage of the modulus of elasticity ratio in the tension part and the compression part of the hysteresis loops,

- a decrease of a certain percentage of the maximum tensile stress in relation to the maximum compressive stress.

Failure criteria are thus related to a decrease in resistance or stiffness. In the specific case of the TBS, the level of resisting force is not a failure criterion, as the climatic action is an imposed displacement. It is more logical to link the failure criterion to the loss of resistance of the TBS under vertical action. As a consequence, the specimen will be considered as collapsed when a rapid increase of the rotation of the TBS is observed.

Due to the fact that the value of the balcony rotation is not known during the tests but after some mathematical operations using the measured values of the vertical displacement, the loading is continued until the concrete block suspended to the balcony drops and reaches the floor. The failure point can be then determined by evaluating the evolution of the balcony rotation. This method can be referred to the third criteria described above, given the fact that the increase of balcony deflection can be assimilated to a decrease of rotational stiffness. 


\subsection{Test results}

This section presents the hysteretic cyclic response of the TBS, the failure modes and the evolution of the jack force and the rotation of the balcony with the number of loading cycles. In order to avoid any confusion, the number of cycles will be counted in half-sine cycles in the article.

\subsubsection{Hysteretic cyclic response}

In the following, we present the mechanical behaviour of the TBS under an incremental cyclic loading. The force-displacement response of TBS under cyclic loading is depicted in Fig. 10 for all specimens except $\mathrm{CH} 2$ and $\mathrm{CH} 6$ since the loading amplitude of those two are the same as $\mathrm{CH} 1$ and $\mathrm{CH} 5$, respectively. We can observe that the effect of concrete damaging is apparent in the unloading branches through pinching.
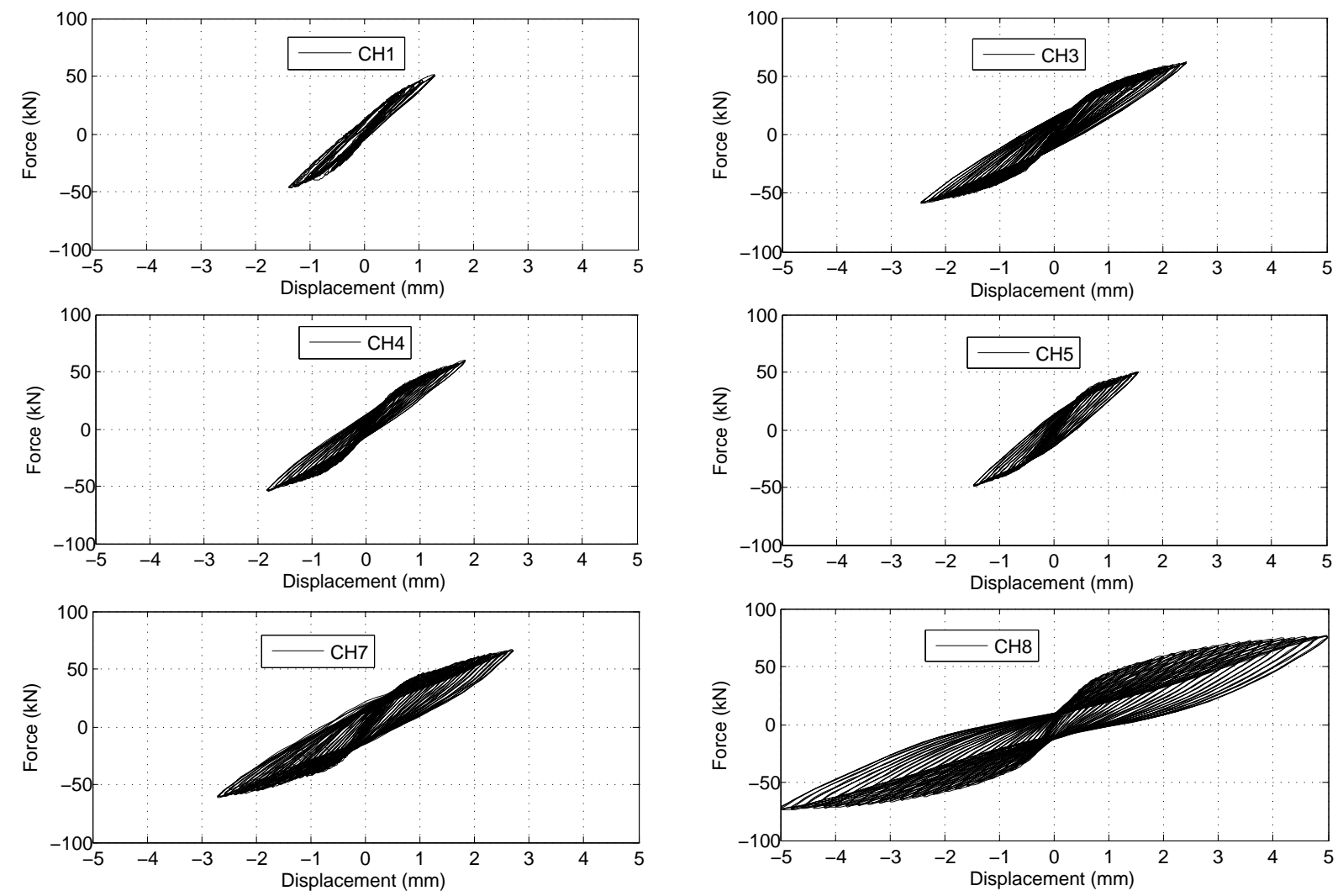

Figure 10: Hysteretic cyclic response. 


\subsubsection{Failure modes}

Even for the tests with the lowest amplitudes, the deformation of the U-shaped steel is visible to the naked eye. A slight uplift of the end plates can even be observed. Nevertheless, this has no impact on the fatigue strength of the thermal break.. The failure modes are similar for all the specimens subjected to a small to moderate displacement amplitude (CH1 to CH7). They are associated with the propagation cracks in U-shaped steel sections. The loading is continued and the first cracks are observed at the first hundred of cycles on both U-shaped steel sections, propagating diagonally from the hole at the end of the balcony-side slot towards the flanges of the U-section. After continuing loading, other cracks are initiated in the welds or from the screws. At the end, cracks propagate in the flanges. Consequently, the compression resistance of the thermal break system drops significantly, resulting in an increasing balcony rotation until the concrete block suspended to the balcony reaches the floor. These failure modes are categorized as type I and type II in Table 3. The type III is observed only for the specimens $\mathrm{CH} 7$ and $\mathrm{CH} 8$, which have been submitted to a very large loading amplitude. In this case, the collapse is guided by concrete crushing.

The failure mode of each specimen is listed in Table 4. It is worth mentioning that the complete failure of the specimen $\mathrm{CH} 1$ has not been attained during the test, i.e the loading has not been continued until the concrete block, suspended to the balcony, drops and reaches the floor. The loading has been stopped at 36000 half-cycles. However, at the last loading cycle, the force amplitude had dropped by $22 \%$ and the rotation of the balcony had increased by $34 \%$ compared to the values at the beginning of the test. As a result, the number of half-cycles of 36000 is considered as the number of cycles that the specimen $\mathrm{CH} 1$ can sustain with the applied displacement amplitude of $1.22 \mathrm{~mm}$.

\subsubsection{Evolution of jack force and balcony rotation}

The jack force measurement using DELTECH $\pm 200 \mathrm{kN}$ sensor is recorded regularly throughout the test. The evolution of the force amplitude can be separated into two stages. A linear decrease in the force amplitude per cycle is observed during the first stage of the test for all specimens, see Fig. 11. At the second stage, the slope of the force amplitude-number of cycle curve drops more 
Table 3: Failure mode description.

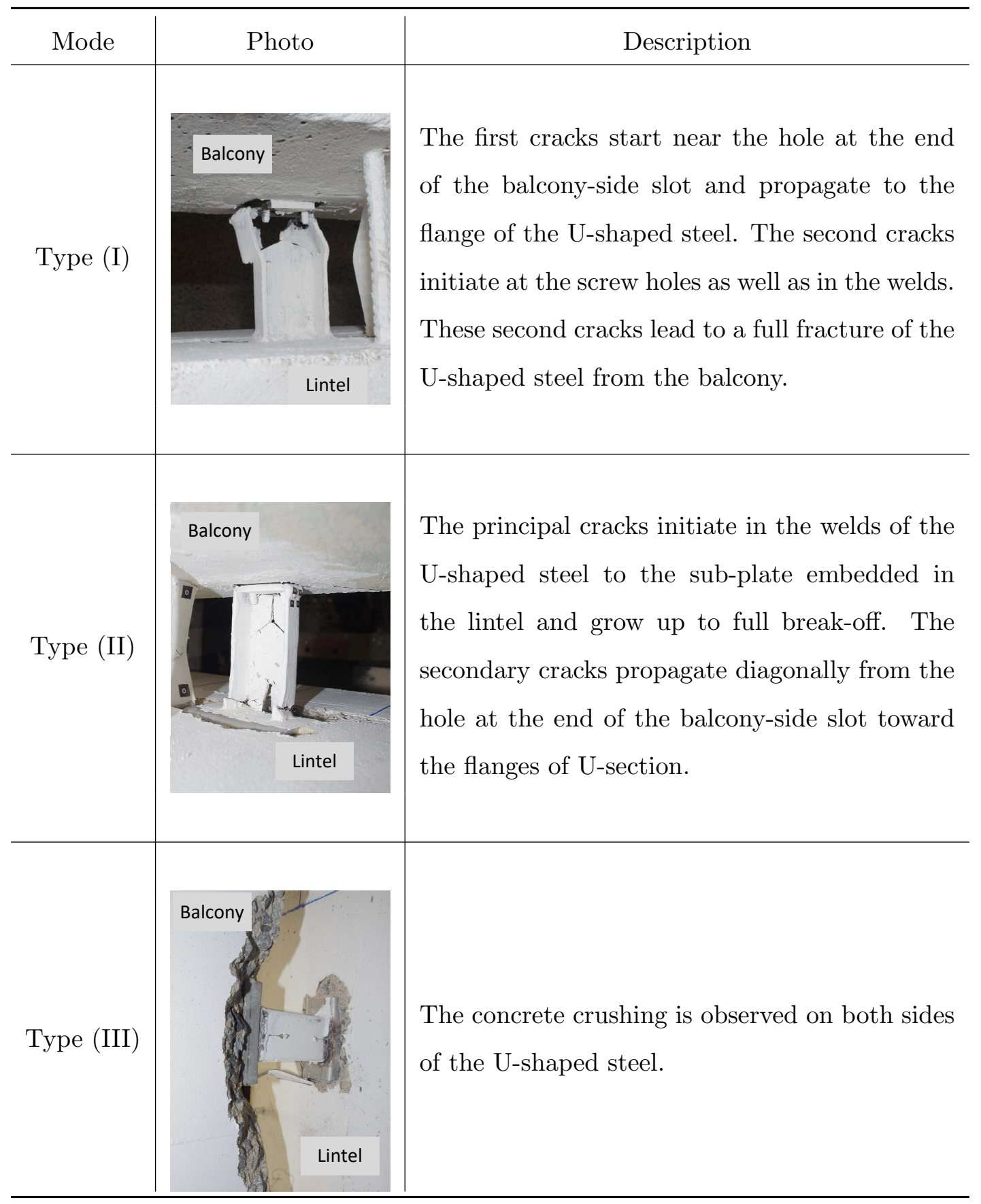

Table 4: Failure mode of each specimen.

\begin{tabular}{ccccccccc}
\hline Specimen & CH1 & CH2 & CH3 & CH4 & CH5 & CG6 & CH7 & CH8 \\
\hline Failure mode & $(\mathrm{I})$ & $(\mathrm{I})$ & $(\mathrm{II})$ & $(\mathrm{I} \& \mathrm{II})$ & $(\mathrm{I} \& \mathrm{II})$ & $(\mathrm{I})$ & $(\mathrm{I} \& \mathrm{III})$ & $(\mathrm{III})$ \\
\hline
\end{tabular}




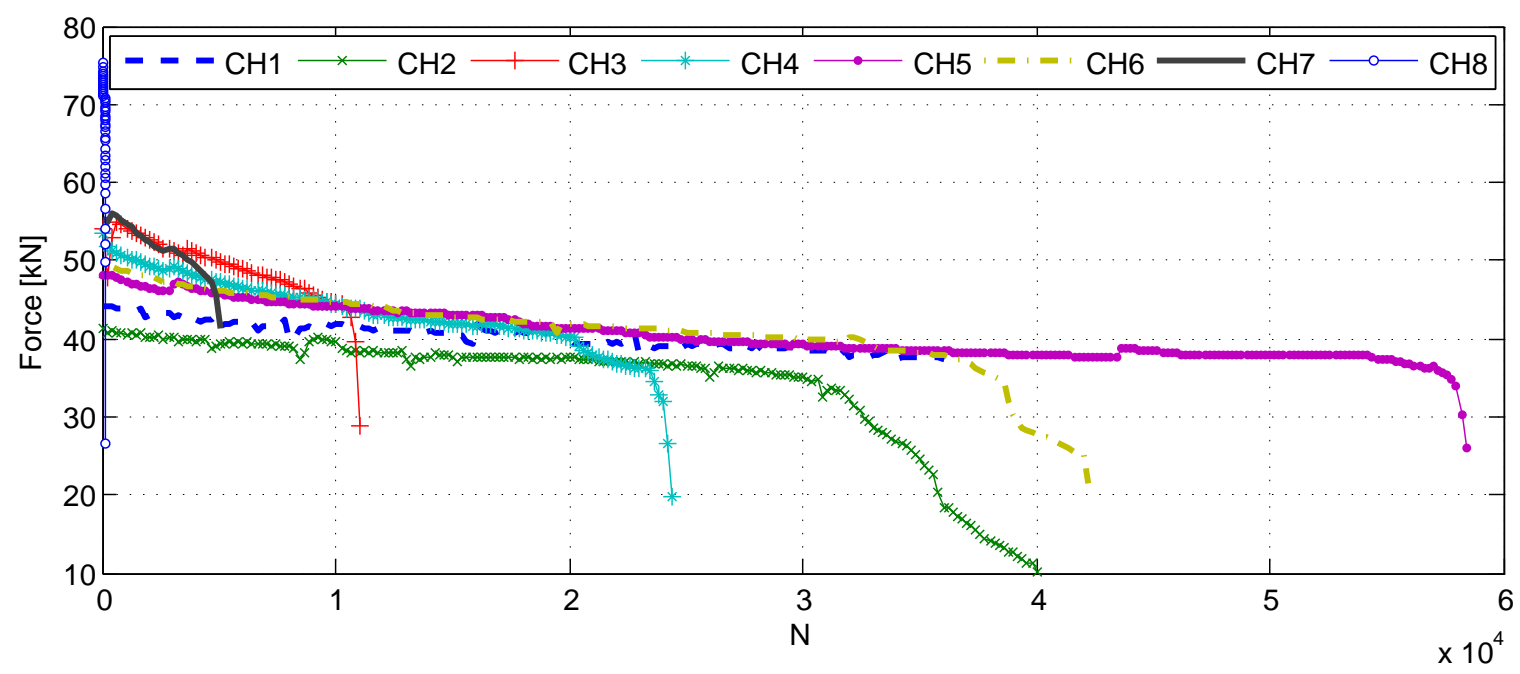

Figure 11: Evolution of jack force as a function of number of cycles.

or less suddenly, indicating the last stage before the complete failure of the specimen.

The rotation of the balcony with respect to the RC slab at the position of the thermal break is determined by using the measurement of the vertical displacement of the whole specimen. The evolution of the balcony rotation for all specimens are illustrated in Fig. 12. It can be seen that there is the same phenomenon, as observed in the evolution of the force amplitude, in the evolution of the balcony rotation. The first stage of the latter corresponds to its linear growth while the second stage is associated with its significant growth indicating the beginning of the failure. The ultimate rotation is chosen at the transition between these two stages.

Table 5 resumes the results of cyclic tests at the failure point in which $x_{a}$ is the horizontal imposed displacement at failure, $\theta_{b}$ is the ultimate rotation of the balcony , $F_{a}$ is the force amplitude recorded at the ultimate stage, $N_{f}$ is the number of half-sinusoidal cycles attained at the failure point, and $V_{c p}$ is the mean velocity of diagonal crack propagation.

\section{Force-displacement relationship for the TBS}

Based on the horizontal cyclic loading test results, the force-displacement relationship for the TBS is developed. The development of the latter is based on plastic-damage model [12] which was initially developed for modelling concrete material. The force-displacement relationship will serve later for implementing the low-cycle fatigue design criterion for the TBS. 


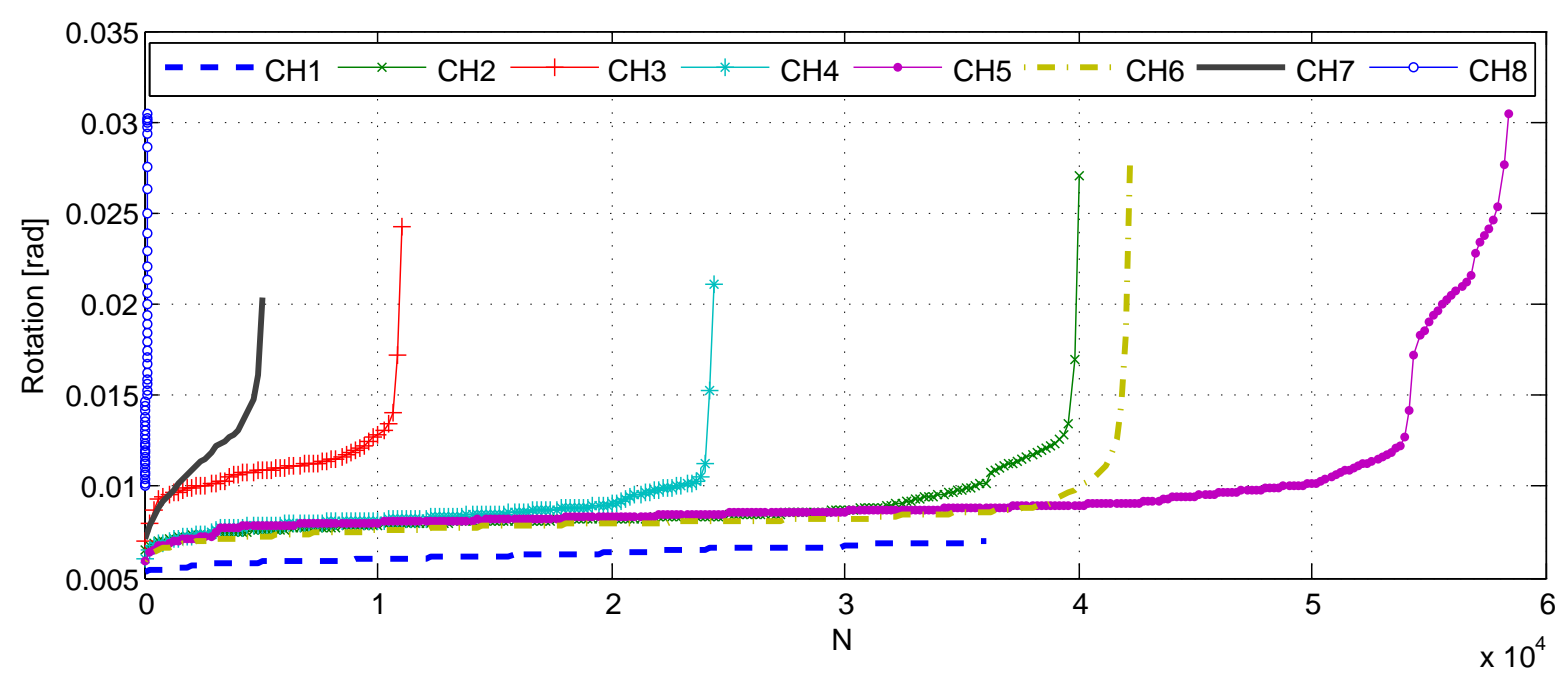

Figure 12: Evolution of balcony rotation as a function of number of cycles.

Table 5: Results at assumed failure.

\begin{tabular}{cccccr}
\hline Specimen & $x_{a}[\mathrm{~mm}]$ & $\theta_{b}[\mathrm{rad}]$ & $F_{a}[\mathrm{kN}]$ & $N_{f}$ & $V_{c p}\left[\mathrm{~mm} / N_{f}\right]$ \\
\hline $\mathrm{CH} 1$ & 1.22 & 0.0139 & 37.844 & 36000 & 0.001232 \\
$\mathrm{CH} 2$ & 1.22 & 0.0174 & 34.999 & 30000 & 0.001479 \\
$\mathrm{CH} 3$ & 2.44 & 0.0229 & 46.961 & 8000 & 0.005612 \\
$\mathrm{CH} 4$ & 1.83 & 0.0180 & 40.315 & 20000 & 0.002224 \\
$\mathrm{CH} 5$ & 1.52 & 0.0255 & 38.027 & 54000 & 0.00082 \\
$\mathrm{CH} 6$ & 1.52 & 0.0172 & 37.864 & 36000 & 0.001232 \\
$\mathrm{CH} 7$ & 2.75 & 0.0295 & 47.251 & 4600 & 0.009876 \\
$\mathrm{CH} 8$ & 5.00 & 0.0388 & 67.078 & 68 & - \\
\hline
\end{tabular}

\subsection{Force-displacement envelope curve}

Assuming that the total horizontal displacement $(x)$ can be decomposed into elastic $\left(x^{e}\right)$ and plastic-damage $\left(x^{p d}\right)$ components, the generalised force $(F)$ versus generalised displacement $(x)$ can be described by the following equation:

$$
x=x^{e}+x^{p d}=\frac{F}{k^{e}}+\left(\frac{F}{k^{\prime}}\right)^{1 / n^{\prime}}
$$

where $k^{e}$ is the elastic stiffness; $k^{\prime}$ is the cyclic coefficient and $n^{\prime}$ is the cyclic hardening exponent. Eq. (1) is similar to the one proposed by Ramberg and Osgood [13] which is applied for true stress and true strain relationship for ductile materials as stainless steel. Eq. (1) is totally empirical. The 
parameter $n^{\prime}$ is without unit. The coefficient $k^{\prime}$ can be interpreted in logarithm scale of $F$ and $x^{p d}$. Rewriting the relation of $x^{p d}$ and $F$ in logarithm scale, we have:

$$
\log F=n^{\prime} \log x^{p d}+\log k^{\prime}
$$

which means that $k^{\prime}$ is equal to $F$ when the plastic-damage displacement $x^{p d}$ is equal to unity. The plastic-damage displacement $x^{p d}$ can be calculated by the following equation:

$$
x^{p d}=x-\frac{F}{k^{e}} .
$$

The results of $\mathrm{CH} 3, \mathrm{CH} 7$ and $\mathrm{CH} 8$ cyclic tests are chosen to develop the envelope curve, see Fig. 13 . It is assumed that the system performs symmetrically in both directions (compression and tension). As a result, only one envelope curve for both directions is developed. It is worth mentioning that only the force attained at the third cycle of each amplitude of displacement is used and the value of the force presented in Fig. 13 is the mean value of the ones in compression and in tension with the same amplitude of displacement. By using the least-square fitting regression, we obtain the following parameters for the envelope curve: the initial stiffness $k^{e}=72.83 \mathrm{kN} / \mathrm{mm} ; k^{\prime}=54.21$; and $n^{\prime}=0.2407$.

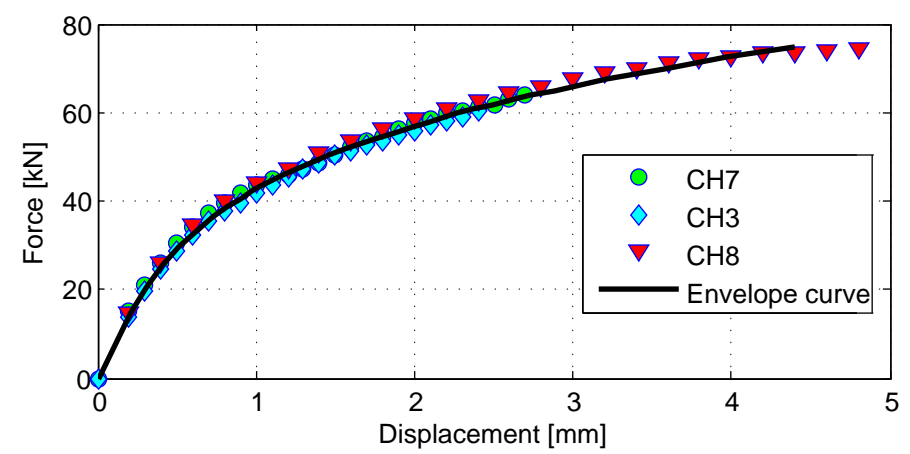

Figure 13: Envelope curve.

\subsection{Cyclic force-displacement relationship}

As presented previously in Section 3.1, a non-recoverable displacement as well as a degradation of the stiffness of the unloading branch is observed, see Fig. 10. This phenomenon, known as the coupling between plasticity and damage occurring on brittle materials like concrete, can be modelled by means of an extension of classical plasticity theory. The detail of the model development is 
presented in Appendix A. The model parameters $\zeta, \beta$ and $H$ are determined in the way that the force-displacement curve is well described. After several attempts, we observe that the values of -0.99 for $\zeta, 0.01$ for $\beta$ and 20 for $H$ give the finest force-displacement curve while compared to the experimental results, see Fig. 14. One can observe that the coupled damage-plasticity model represents well the global behaviour of the TBS under cyclic horizontal loading. Indeed, there is a good estimation of plastic displacement while the system is completely unloaded (zero force) even if the linear unloading is assumed in the model.
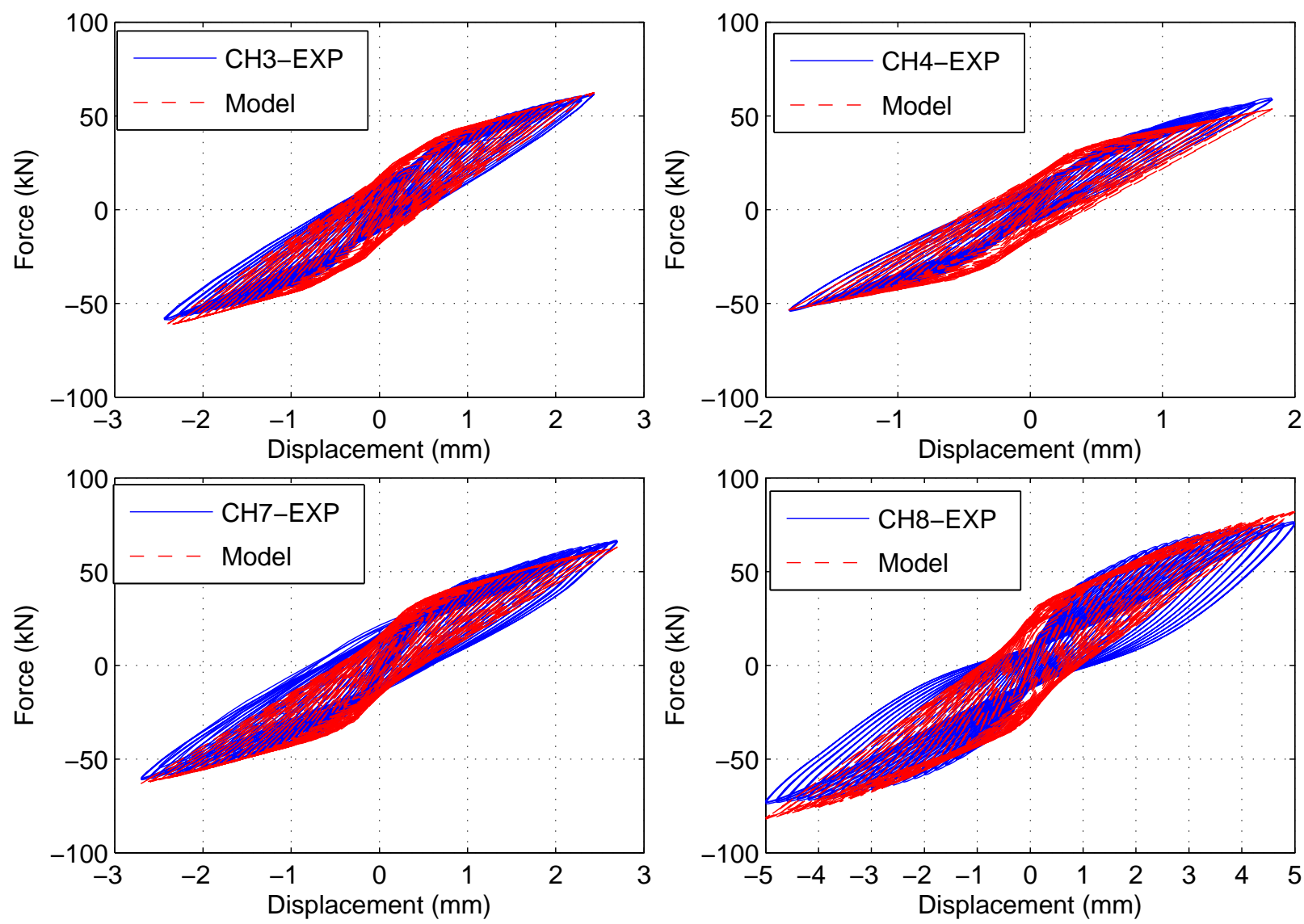

Figure 14: Comparison of coupled damage-plasticity model against experimental results.

\section{Fatigue life design criterion for TBS-SUNE}

\subsection{Introduction}

To perform fatigue analysis, two of the common empirical approaches can be used: stress-life or strain-life method. In the stress-life approach, the failure life of a structural component is 
estimated based upon the magnitude of the alternating stresses. One of the major drawbacks of this approach is that it ignores the actual material response and treats all the behaviour as elastic. This generally results in an overestimation of the fatigue life when the plastic strain contribution is significant, particularly for the stainless steel. Thus, the stress-life method may not be applicable when the plastic strain is not negligible, in low-cycle fatigue for example. Alternatively, the strainlife approach estimates fatigue life using the total strain amplitude, including both the plastic and elastic strain contributions. Thus, the strain-life methods can be applied in low-cycle fatigue where significant plastic strains are present.

The relation between the fatigue life and elastic strain amplitude was first identified by Basquin [14], who proposed a linear relationship between the logarithm of the stress amplitude and the logarithm of fatigue life. The intercept at one stress reversal is defined as the fatigue strength coefficient, $\sigma_{f}^{\prime}$, and is usually approximated by the true fracture strength of the metal. The fatigue strength exponent (also known as Basquin's exponent), $b$, is defined as the slope of the line. Thus, the stress amplitude can be written as

$$
\sigma_{a}=\sigma_{f}^{\prime}\left(N_{f}\right)^{b}
$$

where $\sigma_{a}$ is the stress amplitude and $N_{f}$ is the fatigue life. The relationship between elastic strain amplitude, $\varepsilon_{a}^{e}$, and fatigue life is then given as

$$
\varepsilon_{a}^{e}=\frac{\sigma_{a}}{E}=\frac{\sigma_{f}^{\prime}}{E}\left(N_{f}\right)^{b}
$$

where $E$ is the modulus of elasticity. The relationship between fatigue life and the plastic strain amplitude was independently identified by Coffin Jr [15] and Manson [16]. They found a linear relation between the logarithm of the fatigue life and the logarithm of the stable plastic strain amplitude, $\varepsilon_{a}^{p}$, which can be written as

$$
\varepsilon_{a}^{p}=\varepsilon_{f}^{\prime}\left(N_{f}\right)^{c}
$$

where $\varepsilon_{f}^{\prime}$ is defined as the fatigue ductility coefficient and $c$ is the fatigue ductility exponent which is the slope of the line. In cyclic fatigue experiments, the fatigue ductility coefficient, $\varepsilon_{f}^{\prime}$, is usually determined from the plastic strain intercept at one load reversal using the $0.2 \%$ offset yield strength [17. The strain-life method recognises that there is a transition from predominantly elastic effects 
to predominantly plastic effects. Combining Eqs. (5) and (6) yields the so-called Manson-Coffin's strain-life equation:

$$
\varepsilon_{a}=\varepsilon_{a}^{e}+\varepsilon_{a}^{p}=\frac{\sigma_{f}^{\prime}}{E}\left(N_{f}\right)^{b}+\varepsilon_{f}^{\prime}\left(N_{f}\right)^{c}
$$

For a constant amplitude cyclic loading, Eq. (7) allows the number of cycles to failure to be determined given the constant strain amplitude, $\varepsilon_{a}$, and the values of the material constants. The material parameters can be obtained from monotonic and cyclic experiments. The strain amplitude is obtained directly through strain measurement at critical locations or indirectly, either analytically or approximately using finite element method.

From the perspective of applied cyclic stresses, fatigue damage of a component correlates strongly with the applied stress amplitude. Experimental results indicate as well that the mean stress influences very significantly on the total fatigue life [18. In conjunction with the local strain life approach, many models have been proposed to quantify the effect of mean stresses on fatigue behaviour. The commonly used models in the ground vehicle industry are those by Morrow [19] and by Smith et al. [20]. Morrow proposed the following relationship when a mean stress is present:

$$
\varepsilon_{a}=\frac{\sigma_{f}^{\prime}-\sigma_{m}}{E}\left(N_{f}\right)^{b}+\varepsilon_{f}^{\prime}\left(N_{f}\right)^{c}
$$

In Eq. (8), the elastic part of the strain life curve is modified to take into account the mean normal stress $\left(\sigma_{m}\right)$. This model has been largely used in the long-life regime where plastic strain amplitude is of less significance. Another model which is based on the energy description is proposed by Smith et al. [20], so-called SWT model. It is assumed that the amount of fatigue damage in a cycle is determined by the maximum energy produced in the component, which is the product of the maximum tensile stress $\sigma_{\max }$ and the strain amplitude $\varepsilon_{a}$. The SWT mean stress correction formula is expressed as follows:

$$
\sigma_{\max } \varepsilon_{a}=\frac{\left(\sigma_{f}^{\prime}\right)^{2}}{E}\left(N_{f}\right)^{2 b}+\sigma_{f}^{\prime} \varepsilon_{f}^{\prime}\left(N_{f}\right)^{b+c}
$$

The SWT formula has been demonstrated to be successfully applied to several materials in the range of low and high numbers of cycles by Boller and Seeger [21]. The SWT model is therefore regarded as a more promising model for metallic materials. 


\subsection{Fatigue life prediction for TBS}

Fatigue life criterions exposed above rely on local stresses and strains. This information may be obtained in the present case by direct measurement or by local finite element analyses. However, due to the geometry of the specimen, the direct measurement is very demanding. On the other hand, the behaviour of the contact at the steel-concrete interface and of the concrete under the local compression of the $\mathrm{U}$ profile, that have an important impact on these local stresses and strains, are hardly represented in FE analyses. As a result, rather than entering in an uncertain complex computation process, it has been decided to assess the TBS as a whole since it is usually adopted for fatigue verifications in civil engineering.

Similar to SWT model, an energy-based fatigue criterion was proposed by Jahed and VarvaniFarahani [22] to assess the fatigue lives of engineering components, which is expressed as:

$$
\Delta E_{f}=E_{e}^{\prime}\left(N_{f}\right)^{B}+E_{f}^{\prime}\left(N_{f}\right)^{C}
$$

where $\Delta E_{f}$ is the energy due to the applied loading, $E_{f}^{\prime}$ the fatigue toughness, $E_{e}^{\prime}$ the strength coefficient, $C$ the toughness exponent and $B$ is the fatigue strength exponent. Comparably to Manson-Coffin's equation, Eq. 10 is composed of elastic and plastic energy-life curve which corresponds to elastic and plastic energy contribution, respectively.

This approach can be used for TBS by forming the generalised force and displacement signal following the force-displacement relationship described in Section 3 . However, under variableamplitude cyclic loading, applying directly Eq. 10 may be not appropriate since the counting of loading cycles may be inadequately performed. To overcome this shortcoming, the energy term is replaced by the product of maximum absolute-generalised forces during loading cycle, $F_{\max }$ and the generalised displacement amplitude $x_{a}$; Eq. (10) is then modified to

$$
\Delta E_{f}^{\max }=F_{\max } x_{a}=E_{e}^{\prime}\left(N_{f}\right)^{B}+E_{f}^{\prime}\left(N_{f}\right)^{C}
$$

which is similar to SWT model. It should be noted that $F_{\max } x_{a}$ is not the internal energy, but an external work-like term. Since a low-cycle fatigue life of TBS is focused here, only the plastic energy-life part of Eq. (11) is considered. Energy-fatigue life equation (Eq. (11)) is then reduced to:

$$
\Delta E_{f}^{\max }=F_{\max } x_{a}=E_{f}^{\prime}\left(N_{f}\right)^{C}
$$


Hence, the energy-fatigue life curve for TBS is constructed based on Eq. (12), see Fig. 15. The model parameters can be obtained by applying a linear regression analysis presented in the following section.

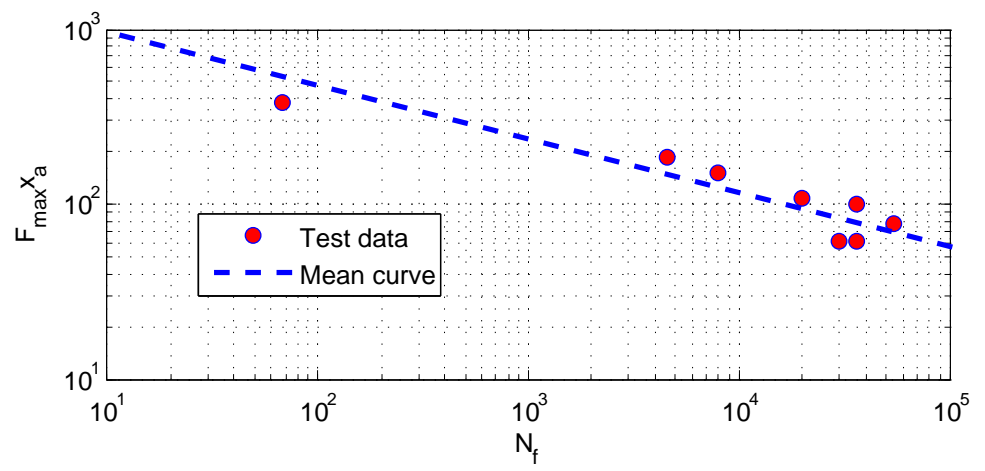

Figure 15: $\Delta E_{f}^{\max }-N_{f}$ mean curve.

\subsection{Design fatigue curve}

The $\Delta E_{f}^{\max }-N_{f}$ curve is evaluated from the fatigue test results. When the fatigue test results are plotted on a log-log scale, i.e. log (energy range,) versus log (number of cycles to failure) a scatter is observed in the fatigue data, see Fig. 15. To evaluate the data, a statistical analysis needs to be performed by applying a technique of standard linear regression analysis.

From the energy-fatigue life model, one can obtain the following linear relationship between $\log \left(\Delta E_{f}^{\max }\right)$ and $\log \left(N_{f}\right)$

$$
\log \left(N_{f}\right)=-\frac{1}{C} \log \left(E_{f}^{\prime}\right)+\frac{1}{C} \log \left(\Delta E_{f}^{\max }\right)
$$

Let

$$
Y=\log \left(N_{f}\right) ; \quad X=\log \left(\Delta E_{f}^{\max }\right) ; \quad a=-\frac{1}{C} \log \left(E_{f}^{\prime}\right) ; \quad b=\frac{1}{C}
$$

where $\log$ is the base-10 logarithm. The estimated values of $a$ and $b$ denoted by $\bar{a}$ and $\bar{b}$, respectively, are determined by the linear regression analysis which leads to the following equations:

$$
\begin{aligned}
& \bar{b}=\frac{n \sum_{i=1}^{n} X_{i} Y_{i}-\left(\sum_{i=1}^{n} X_{i}\right)\left(\sum_{i=1}^{n} Y_{i}\right)}{n \sum_{i=1}^{n} X_{i}^{2}-\left(\sum_{i=1}^{n} X_{i}\right)^{2}} \\
& \bar{a}=\bar{Y}-\bar{b} \bar{X}
\end{aligned}
$$


where $\bar{Y}$ and $\bar{X}$ are respectively the means of $Y$ and $X$; and $n$ is the number of data points (sample size). Using the above equations, we obtain:

$$
\bar{b}=-3.259 \text { and } \quad \bar{a}=10.735 \text {. }
$$

In order to get a low estimation of the fatigue life, the characteristic curve must be determined. It is assumed that it has the same slope as the mean curve, i.e. $b_{k}=\bar{b}=-3.259$. Thus, the $\Delta E_{f}^{\max }-N_{f}$ design curve can be obtained by calculating the characteristic value of the parameter $a$. The latter can be found using the approach described in Annex D of EN 1990 [6]. The characteristic value $a_{k}$ is determined statistically from the test results, taking into account a confidence level of at least 0.75 . It is assumed that for any fixed values of $X_{i}=\log \left(\Delta E_{f, i}^{\max }\right)$, the corresponding values of $a_{i}=Y_{i}-\bar{b} X_{i}$ form a normal distribution and then, in the absence of other information, the characteristic value can be assumed to be the 0.05 fractile of a normal distribution. The characteristic value is then estimated by the following relation:

$$
a_{k}=\bar{a}-k_{s} s_{a}
$$

where $s_{a}$ is the sample standard deviation of $a_{i}$; their values are listed in Table 6 . The value of $k_{s}$ can be obtained using Table 7 where the sample standard deviation is not known from prior knowledge and is needed to be estimated from the sample. With 8 sample tests, $k_{s}$ can be taken

Table 6: The value of $a_{i}$ corresponding to each data point from the tests and its standard deviation, $s_{a}$

\begin{tabular}{l|cccccccc}
\hline$a_{i}$ & 10.394 & 10.305 & 11.001 & 10.943 & 10.872 & 11.071 & 11.040 & 10.252 \\
\hline$s_{a}$ & 0.353 & & & & & & & \\
\hline
\end{tabular}

\begin{tabular}{|c|c|c|c|c|c|c|c|c|c|}
\hline \multirow{2}{*}{$\begin{array}{c}\text { Probability } \\
\text { P }\end{array}$} & \multicolumn{9}{|c|}{ Number of tests, $\mathrm{n}$} \\
\hline & 3 & 4 & 5 & 6 & 8 & 10 & 20 & 30 & $\infty$ \\
\hline 0.05 & 3.37 & 2.63 & 2.33 & 2.18 & 2.00 & 1.92 & 1.76 & 1.73 & 1.64 \\
\hline
\end{tabular}

Table 7: Values of $k_{s} ; s_{a}$ unknown (Confidence level $\left.=0.75\right)$

equal to 2, which leads $a_{k}$ equal to 10.029. Replacing the characteristic value $a_{k}$ and $b_{k}$ in Eq. (14), solving for $C$ and $E_{f}^{\prime}$ and back substituting the results in Eq. (13), the $\Delta E_{f}^{\max }-N_{f}$ characteristic curve can be finally constructed, see Fig. 16 . 
The design value of a product property is determined using its characteristic value being divided by a partial factor $\gamma_{m}$ and by multiplying, if applicable, a conversion factor $\eta$. $\gamma_{m}$ accounts for the unfavorable uncertainties on the characteristics of this product property as well as any local defaults while $\eta$ is to consider scale effects. The design value of $a$ is therefore given by

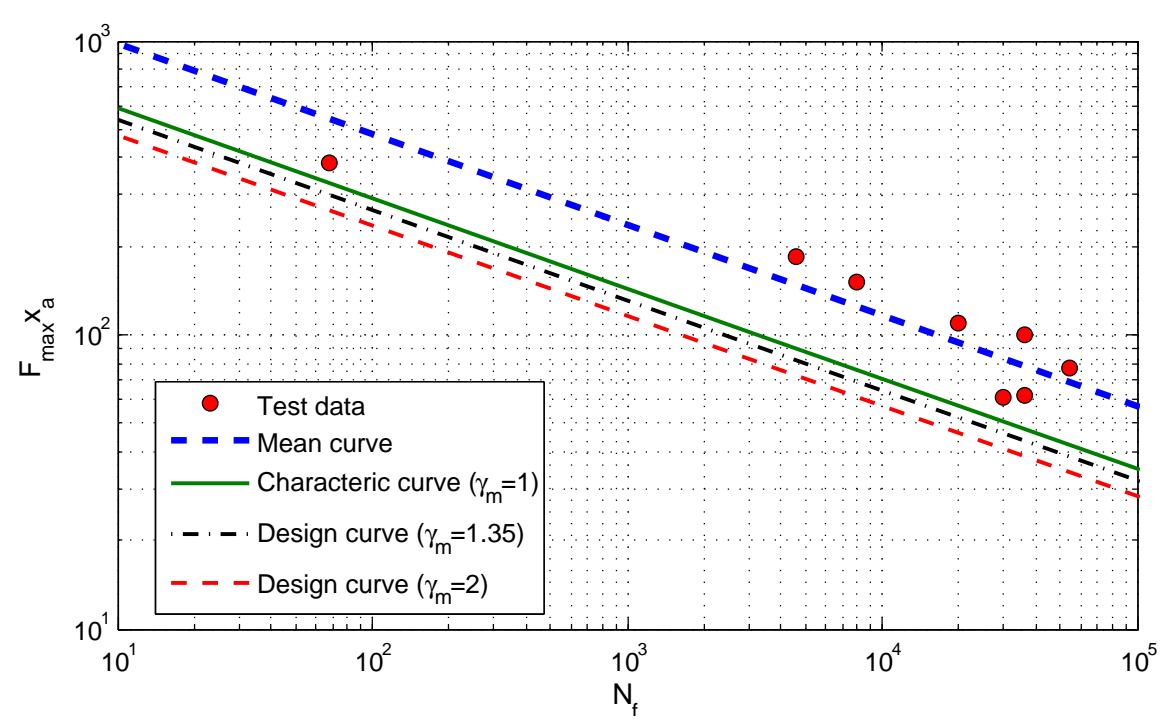

Figure 16: $\Delta E_{f}^{\max }-N_{f}$ curves.

$$
a_{d}=\log _{10}\left(\frac{\eta}{\gamma_{m}}\right)+a_{k}=\log _{10}\left(\frac{\eta}{\gamma_{m}}\right)+\left(\bar{a}-k_{s} \sigma_{a}\right) .
$$

Since the fatigue tests have been performed in real-scale specimens, the conversion factor $\eta$ can be assumed to be equal to 1 . The choice of partial factor $\gamma_{m}$ value can be taken based on the failure modes of the specimens. It has been observed that the failure modes of the specimen subjected to fatigue loading are mostly related to the fracture of the steel component. As a consequence, it may seem reasonable to adopt $\gamma_{m}=1.35$ as proposed in EC3-1-9 [23] for non fail-safe structural details poorly accessible. However, this value is defined for polycyclic fatigue while low-cycle fatigue is here under consideration. As a consequence, three different values of $\gamma_{m}$ will be considered to get some information on the the sensibility of the design of the TBS to $\gamma_{m} . \Delta E_{f}^{\max }-N_{f}$ curve are drawn in Fig. 16 for $\gamma_{m}=1,1.35,2$.

\subsection{Failure criteria for variable amplitude loading}

In order to deal with a realistic variable amplitude loading on a structure, the linear damage accumulation, so-called "Palmgren-Miner rule" [24] is adopted. In the case of damage accumulation 
methods in combination with $\Delta E_{f}^{\max }-N_{f}$ curve, the verification rule can be presented as

$$
\sum \frac{n_{E, i}}{N_{f, i}}<\frac{D_{c}}{\gamma_{d}}
$$

where

- $n_{E, i}$ is the number of applied load cycles with the loading range level obtained from the rainflow counting procedure;

- $N_{f, i}$ is the number of load cycles at failure for loading range level taking into account the uncertainties in the structural resistance;

- $D_{c}$ is the critical value for the damage ratio, in the ideal case taken equal to 1 ;

- $\gamma_{d}$ is the partial factor that deals with the uncertainties in damage accumulation rule, the design working life and the consequences of failure. Its value is assumed to be equal to 1 .

\section{Thermal action}

As mentioned in Section 1, the balcony suffers climatic hazards and is caused to expand or shorten following the variation of the temperature outside the building. The deformation of the balcony produces then a shear force on the thermal break system. To determine the action effects on the latter, the variation of the temperature has to be known. The procedure to define the temperature data and to obtain the displacement applied to the thermal break system is presented in this section.

\subsection{ECAED temperature database}

European Climate Assessment \& Dataset (ECA\&D) [25] was initiated by the ECSN in 1998 and has received financial support from the EUMETNET and the European Commission. ECA\&D forms the backbone of the climate data node in the Regional Climate Centre (RCC) for WMO Region VI (Europe and the Middle East) since 2010. The data and information products contribute to the Global Framework for Climate Services (GFCS). Today, ECA\&D is receiving data from 68 participants for 63 countries and the ECA data set contains 43271 series of observations for 12 elements at 10586 meteorological stations throughout Europe and the Mediterranean zone. 


\subsection{Factorised temperature distribution}

From the ECA\&D website, we can have the data of the temperature for certain meteorological stations in Europe, particularly in France. The maximum and minimum temperature distribution over the years obtained from ECA\&D database is compared to the distribution of extreme value given by EN 1991-1-5 [26]. Indeed, the maximum (minimum) shade air temperature $T_{\max }\left(T_{\min }\right)$ given by EN 1991-1-5 is supposed to be the value of maximum (minimum) shade air temperature with an annual probability of being exceeded of 0.02 (equivalent to a mean return period of 50 years), based on the maximum (minimum) hourly values recorded. EN 1991-1-5 provides the following expressions based on extreme value distributions of type-I to determine the maximum (or minimum) temperature of the shade air, $T_{\max , p}\left(T_{\min , p}\right)$ based on an annual probability of being exceeded $p$ different from 0.02 :

$$
\begin{aligned}
& T_{\max , p}=T_{\max }\left\{k_{1}-k_{2} \ln [-\ln (1-p)]\right\} \\
& T_{\min , p}=T_{\min }\left\{k_{3}+k_{4} \ln [-\ln (1-p)]\right\}
\end{aligned}
$$

where $k_{1}, k_{2}, k_{3}$ and $k_{4}$ can be taken equal to $0.781,0.056,0.393,-0.156$, respectively.

The comparisons of maximum and minimum annual shade air temperature distribution obtained from several meteorological stations (ECA\&D) and the one given by the default values of EN 19911-5 are illustrated in Fig. 17, where the maximum and minimum shade air temperature $\left(T_{\max }\right.$, $\left.T_{\min }\right)$ are obtained from National Annex (NF EN 1991-1-5/NA). It can be seen from Fig. 17 that there is a large dispersion between the shade air temperature distributions obtained from ECA\&D and the Eurocode one. The Eurocode default curve of the maximum annual shade air temperature distribution does not fit satisfactorily to any meteorological stations while the minimum annual shade air temperature distribution of Eurocode fits satisfactorily to Rennes station which is at the north-west of France.

The value of maximum shade air temperature obtained from ECA\&D with an annual probability of being exceeded of 0.02 does not correspond to the one given by NF EN 1991-1-5/NA. It can be seen that for certain meteorological stations, Rennes for instance, the ratio $T_{\max , p} / T_{\max }$ is significantly greater than 1 . However, it is only one of the cases studied and most of these ratios are lesser than 1 for other stations. We assume that $T_{\max }$ and $T_{\min }$ given by NF EN 1991-1-5/NA are the values that must be considered for design. As a consequence, the signal of temperature 


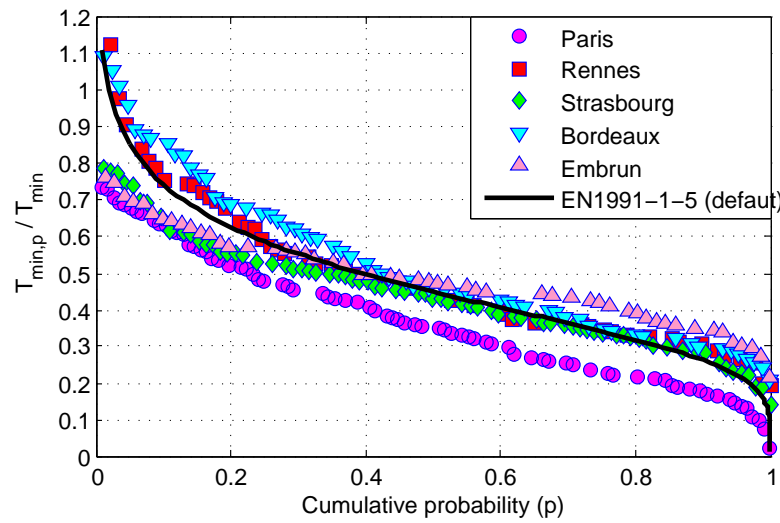

(a) Distribution of minimum annual temperature.

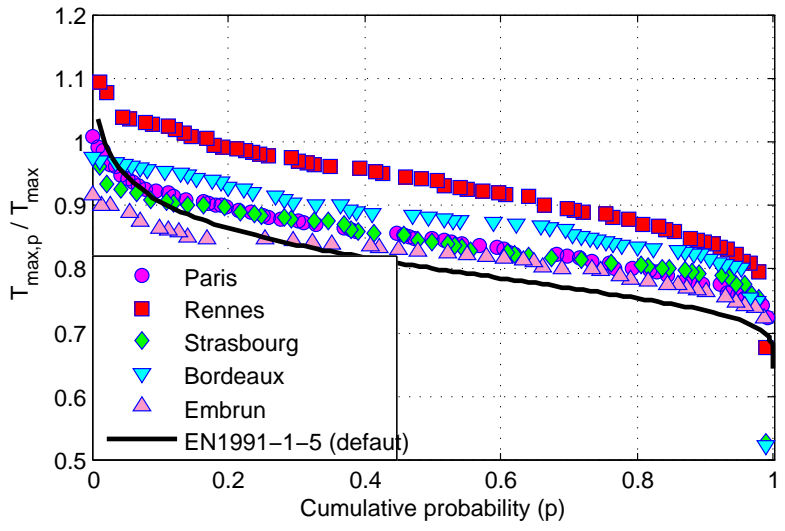

(b) Distribution of maximum annual temperature.

Figure 17: Distribution of annual temperature.

obtained from ECA\&D with $T_{\max , 0.02}$ or $T_{\min , 0.02}$ lesser than $T_{\max }$ or $T_{\min }$ given by NF EN 19911-5/NA must be adopted. To do so, the following linear expansion formulation of the signal is adopted:

$$
T(t)=T_{0}(t)\left[\frac{T_{\max }}{T_{\max , 0.02}}+\left(\frac{T_{\min }}{T_{\min , 0.02}}-\frac{T_{\max }}{T_{\max , 0.02}}\right)\left(\frac{T_{\max , 0.02}-T_{0}(t)}{T_{\max , 0.02}-T_{\min , 0.02}}\right)\right]
$$

where

- $T_{0}(t)$ is the temperature of the initial signal (ECA\&D);

- $T_{\max , 0.02}$ is the maximum temperature of the initial signal with an annual probability of being exceeded of 0.02 ;

- $T_{\min , 0.02}$ is the minimum temperature of the initial signal with an annual probability of being exceeded of 0.02 ;

- $T_{\max }$ is the maximum temperature from NF EN 1991-1-5/NA with an annual probability of being exceeded of 0.02 ;

- $T_{\min }$ is the minimum temperature from NF EN 1991-1-5/NA with an annual probability of being exceeded of 0.02 .

The factorization is performed only when $T_{\max , 0.02}$ is less than $T_{\max }$ or when $T_{\min , 0.02}$ is greater than $T_{\min }$. The temperature distribution after factorizing is shown in Fig. 18, It can be seen that while calibrating $T_{\min , 0.02}$ and $T_{\max , 0.02}$ of the initial signal to $T_{\min }$ and $T_{\max }$ of NF EN 1991-1-5/NA, 
respectively, the factorized maximum as well as minimum temperature with cumulative probability $p$ greater than 0.02 alter to be larger in absolute value. This reshapes the temperature distribution, particularly for maximum temperature, and leads to a wide scatter compared to the ones given by NF EN 1991-1-5.

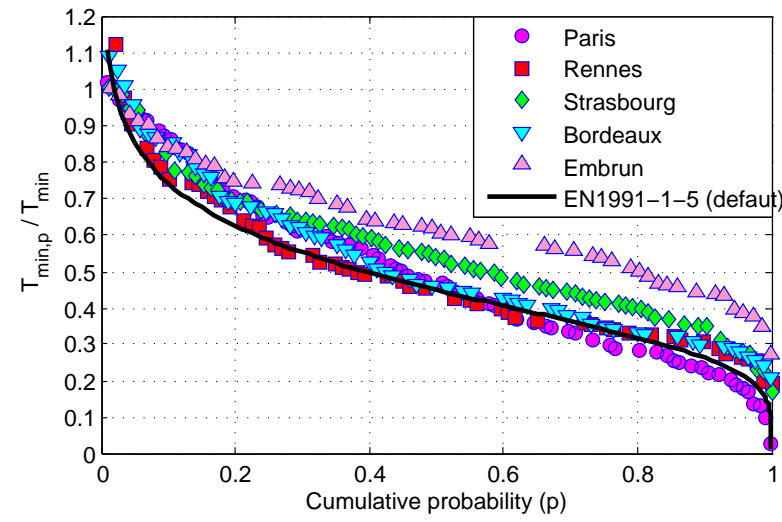

(a) Factorized distribution of minimum annual temperature.

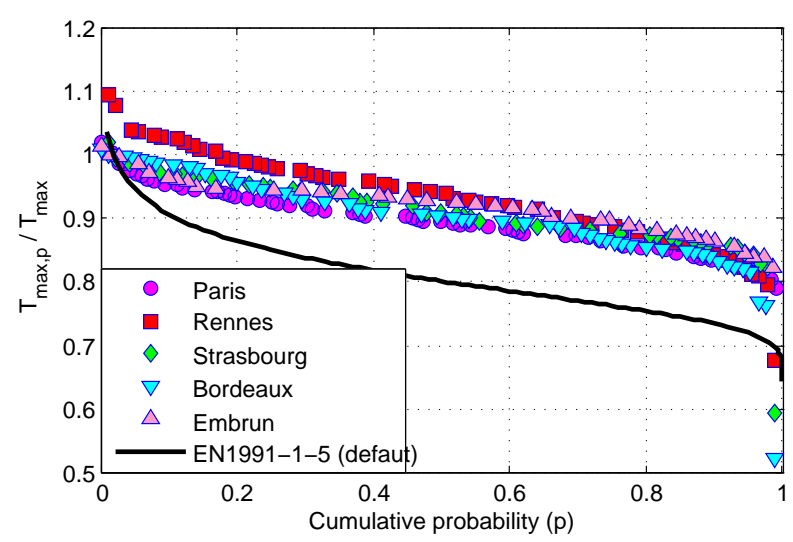

(b) Factorized distribution of maximum annual temperature.

Figure 18: Factorized distribution of annual temperature.

\subsection{Solar radiation}

Solar radiation has important effects in generating heat on the surface of the balcony. For buildings above the ground level, the following values in Table 8 [26] are adopted for solar radiation effects. To be conservative, the dark colored surface is considered. Consequently, there is

Table 8: Indicative temperature $T_{\text {out }}$ for buildings above the ground level.

\begin{tabular}{l|l|l|l}
\hline Season & \multicolumn{2}{|l|}{ Significant factor } & Temperature $T_{\text {out }}$ in ${ }^{\circ} \mathrm{C}$ \\
\hline \multirow{3}{*}{ Summer } & Relative absorptivity & 0.5 Bright light surface & $T_{\max }+T_{3}$ \\
& depending on surface color & 0.7 Light colored surface & $T_{\max }+T_{4}$ \\
& & 0.9 Dark surface & $T_{\max }+T_{5}$ \\
\hline Winter & & $T_{\min }$ \\
\hline
\end{tabular}

Note: $T_{3}=-10^{\circ} \mathrm{C} ; T_{4}=0{ }^{\circ} \mathrm{C} ; T_{5}=10^{\circ} \mathrm{C}$ given by NF EN 1991-1-5/NA.

a modification on the signal of temperature due to solar radiation effects by adding $T_{5}$ to $T_{\max }$ 
defined by the national annex. The daily design temperature (Eq. (23)) is then modified to:

$$
T(t)=T_{0}(t)\left[\frac{T_{\max }+T_{5}}{T_{\max , 0.02}}+\left(\frac{T_{\min }}{T_{\min , 0.02}}-\frac{T_{\max }+T_{5}}{T_{\max , 0.02}}\right)\left(\frac{T_{\max , 0.02}-T_{0}(t)}{T_{\max , 0.02}-T_{\min , 0.02}}\right)\right]
$$

\subsection{Conversion of temperature signal to displacement signal}

From the design temperature obtained by using Eq. (24), we calculate the variation of outdoorindoor temperature $\Delta T$ with respect to time. It is here assumed that the temperature inside the building varies during the year, see Table 9, as estimated by NF EN 1991-1-5 [26]. The horizontal axial deformation of the balcony, supposed to be symmetric from the central axis of the balcony, is then determined from the variation of outdoor-indoor temperature in association with the balcony length, $L_{b}$. This deformation will generate the horizontal displacement imposed to TBS-SUNE at both extremities of the balcony.

\begin{tabular}{c|c} 
Table 9: Temperature inside the building & $T_{\text {inside }}$ \\
\hline Date & $T_{\text {inside }}$ \\
\hline 22 March - 21 June & 22.5 \\
22 June - 21 September & 20.0 \\
22 September - 21 December & 22.5 \\
22 December - 21 March & 25.0 \\
\hline
\end{tabular}

The corresponding displacement is given by:

$$
x=\alpha \Delta T \frac{L_{b}}{2}
$$

where $\alpha=10^{-5}$ is the coefficient of thermal dilatation of concrete and $\Delta T=T(t)-T_{\text {inside }}(t)$.

\section{Verification to thermal loading}

\subsection{Steps of the method and general assumptions}

The verification of TBS against thermal loading can be performed by determining the damage accumulation developed during the building life. This can be done for an existing building where the distribution of temperature is already known. To design a new building where the climate surrounding the building is not yet known during the building life, a probabilistic approach has to be developed. 
It is assumed that the statistical distribution of the climatic action can be computed on the basis of the distribution of the recordings of ECA \& D, transformed as explained in previous paragraphs in order to get thermal amplitudes compliant with actual European standards.

The climatic action in fatigue is defined on the basis of a duration of one year, from 22nd of March to 21st of March, i.e. from spring to spring. The annual accumulated damage $D_{y}$ of the year $\mathrm{i}$ is then obtained from:

$$
D_{y, i}=\sum_{j=1}^{m} \frac{n_{E, j}}{N_{f, j}}
$$

where $m$ is the number of different displacement amplitudes $x_{a, j}$ obtained from rainflow counting technique; $n_{E, j}$ is the number of semi-sinusoidal cycle of each rainflow displacement amplitude $x_{a, j}$; and $N_{f, j}$ is the number of semi-sinusoidal cycle to failure obtained from $\Delta E_{f}^{\max }-N_{f}$ design curve for each rainflow displacement amplitude $x_{a, j}$. In order to use $\Delta E_{f}^{\max }-N_{f}$ design curve, the maximum absolute-generalised forces during loading cycle, $F_{\max }$, is required. The analysis with the annual displacement signal is then primarily performed to capture the corresponding force signal acting on the structure by using the coupled damage-plasticity model developed in this paper. It is worth noting that the rainflow counting algorithm developed by Niesłony [27] is used. This algorithm also provides the start and end point of the loading cycle which can be used to determine the index of the loading cycle, and as a result the value of $F_{\max }$ for each rainflow displacement amplitude $x_{a, j}$.

Processing all the data of ECAD for one station gives a set of values of $D_{y, i}$ that is used to obtain an estimation of the mean value $\widehat{\mu}_{D_{y}}$ and of the standard deviation $\widehat{\sigma}_{D_{y}}$.

The service life is fixed to 50 years in Eurocodes for usual buildings, and the related accumulated damage denoted $D_{50}$ has to be limited to $1 . D_{50}$ is a random variable equal to the sum of 50 annual damages. Each annual damage is supposed to be independent. Hence, according to the central limit theorem, the data set of $D_{50}$, which is a sum of independent random variables, follows a normal distribution $\mathcal{N}\left(50 \widehat{\mu}_{D_{y}}, 50 \widehat{\sigma}_{D_{y}}^{2}\right)$ even if $D_{y, i}$ is not normally distributed. Within a data sample size equal to $n_{\text {year }}$, the characteristic value of $D_{50}$ can be obtained using the following expression:

$$
D_{50, k}=50 \widehat{\mu}_{D_{y}}+t_{v} \sqrt{50} \widehat{\sigma}_{D_{y}}
$$

It is worth mentioning that the available data signal from ECA\&D is usually greater than 50 years and that the value of $t_{v}$ is determined by using the inverse value of Student's cumulative 
distribution function, multiplied by $\sqrt{1+1 / n_{\text {year }}}$.

Since the $\Delta E_{f}^{\max }-N_{f}$ design curve is used to determine the damage parameter, the characteristic value $D_{50, k}$ can be then considered as design value $D_{50, d}$.

\subsection{Computation of the distribution of annual damages based on historical recordings}

The following computation of the distribution of annual damages in Rennes and Embrun cities is done with $\gamma=1$. The temperature and its variations applied for a balcony length of $19 \mathrm{~m}$ from $22 / 03 / 2016$ to $21 / 03 / 2017$ for these cities are chosen for an illustration. Fig. 19 shows the factorized temperature signal in both cities. It can be seen that the factorized temperature signal in Rennes oscillates lesser than the one in Embrun. This is logical, as Rennes is located in a flat area near the atlantic ocean in North-West of France and is subject to a tempered oceanic climate, while Embrun is in the South-East of France in a mountainous region. The histogram

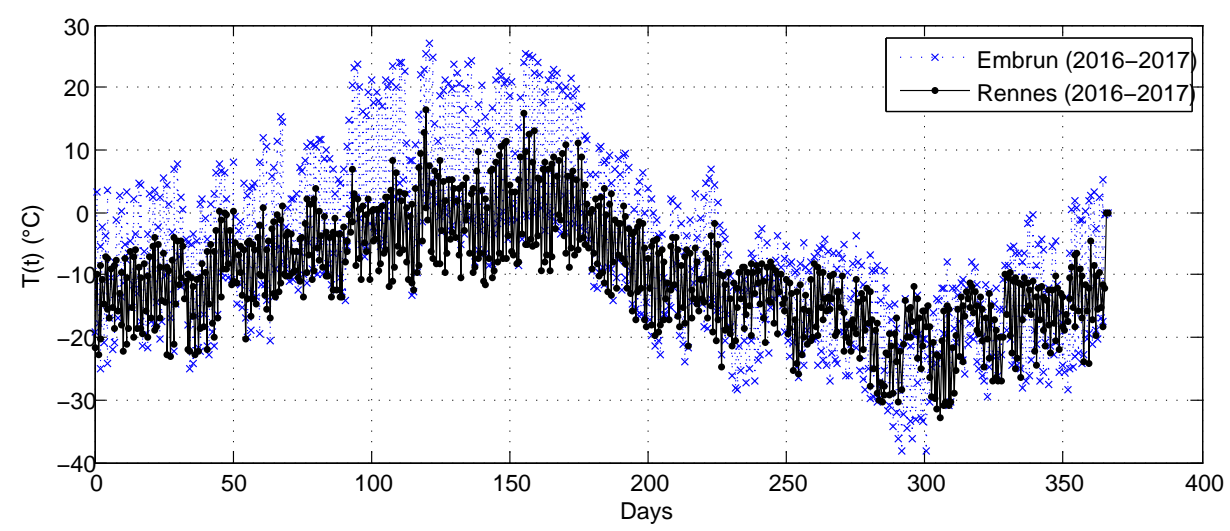

Figure 19: Factorized temperature signal from 22/03/2016 to 21/03/2017.

of inside-outside temperature variation $\Delta T$ of both cities are depicted in Fig. 20. It appears that the most frequent value of $\Delta T$ in Rennes is around $-10{ }^{\circ} \mathrm{C}$ which corresponds more likely to daily temperature variation while in Embrun, the frequent value of $\Delta T$ is in the range of $-20{ }^{\circ} \mathrm{C}$ to 3 ${ }^{\circ} \mathrm{C}$. The minimum annual inside-outside temperature variations are $-33{ }^{\circ} \mathrm{C}$ and $-38{ }^{\circ} \mathrm{C}$ while the maximum are $16{ }^{\circ} \mathrm{C}$ and $27{ }^{\circ} \mathrm{C}$ in Rennes and Embrun, respectively. The displacement signals corresponding to the inside-outside temperature variations on the balcony with $19 \mathrm{~m}$ length are represented in Fig. 21. The rainflow counting algorithm is performed on both displacement signals and the rainflow matrices are illustrated in Figs. 22 and 23 in which $x_{m}$ is the mean value of displacement and $x_{a}$ is the amplitude. It is shown that there are few data with a large amplitude 


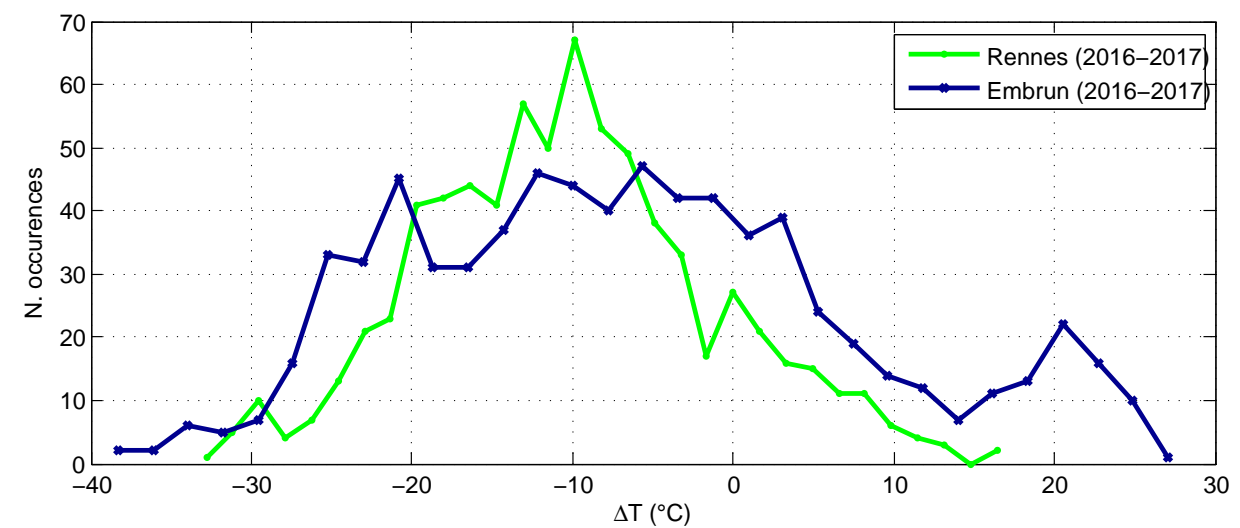

Figure 20: Histogram of inside-outside temperature variation from 22/03/2016 to 21/03/2017.

in the rainflow matrix. Those few data correspond to the annual temperature variations. The large density of rainflow matrix are condensed in the low amplitude range which is more or less related to the daily temperature variation. Besides, a large number of displacement amplitude in the rainflow matrix are larger than $0.5 \mathrm{~mm}$, the displacement amplitude which can induce yielding of the thermal break system, see Fig. 13 . The force signals, see Fig. 24 in response to the

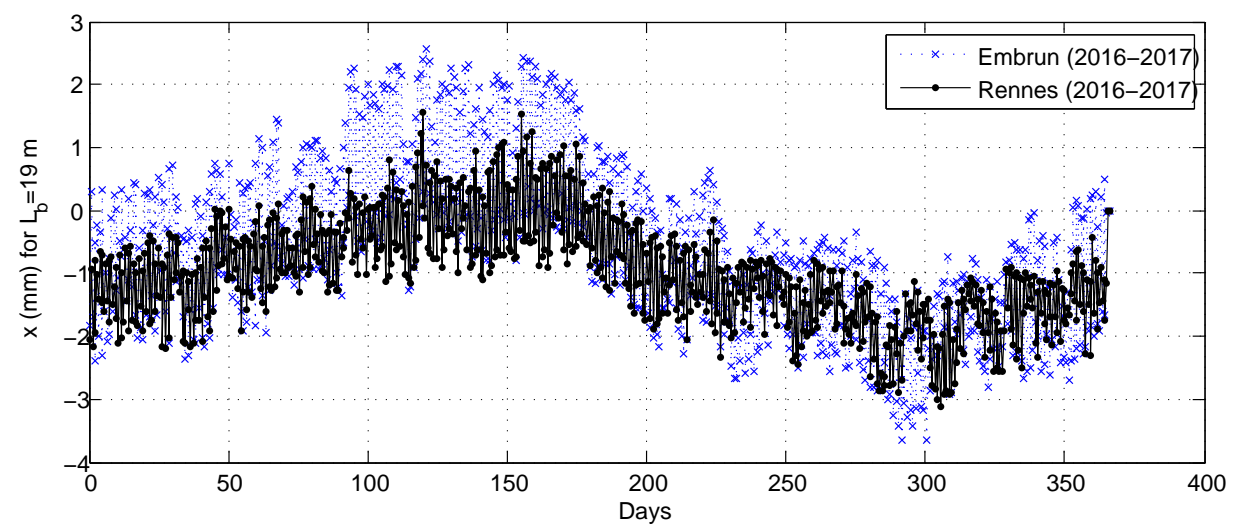

Figure 21: Displacement signal for $L_{b}=19 \mathrm{~m}$.

displacement signals, are obtained by performing the analyses using the coupled damage-plasticity model. From the force signal, the absolute value of maximum force $F_{\max }$ during the the rainflow loading cycle can be obtained. The histogram of $\Delta E_{f}^{\max }=F_{\max } x_{a}$ for each city can be constructed, see Figs. 25 and 26. It is clear that the value and frequency of $\Delta E_{f}^{\max }$ developed on the thermal 


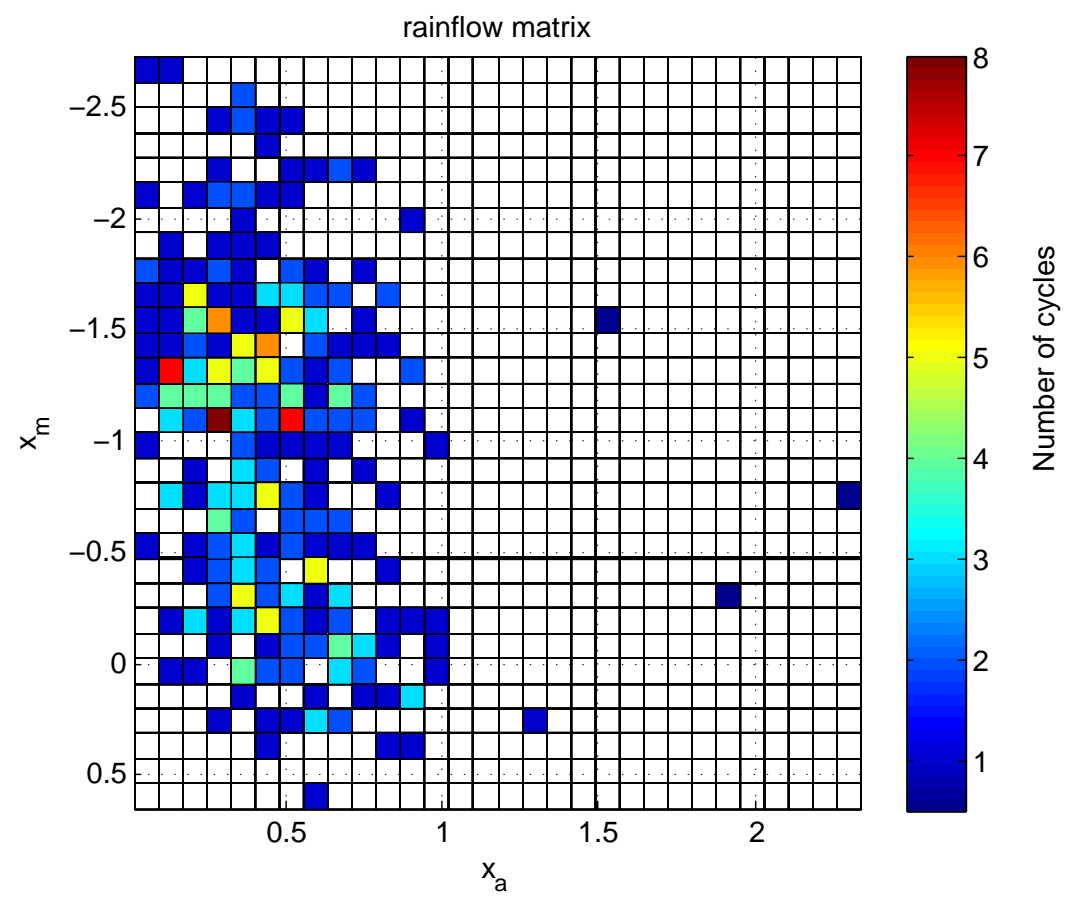

Figure 22: Rainflow matrix of displacement signal in Rennes.

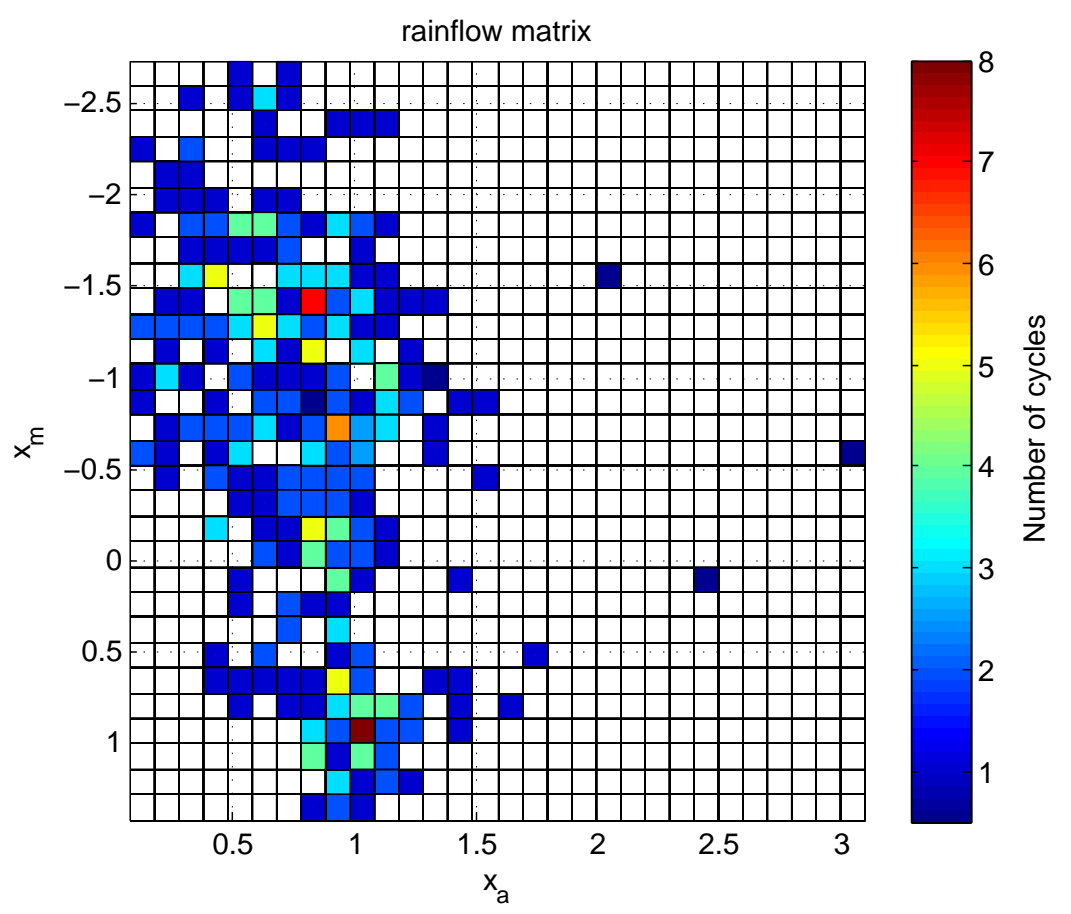

Figure 23: Rainflow matrix of displacement signal in Embrun.

break system while being used in the buildings in Embrun is larger than the one in Rennes. As a result, the annual accumulated damage in Embrun is larger than the one in Rennes. 


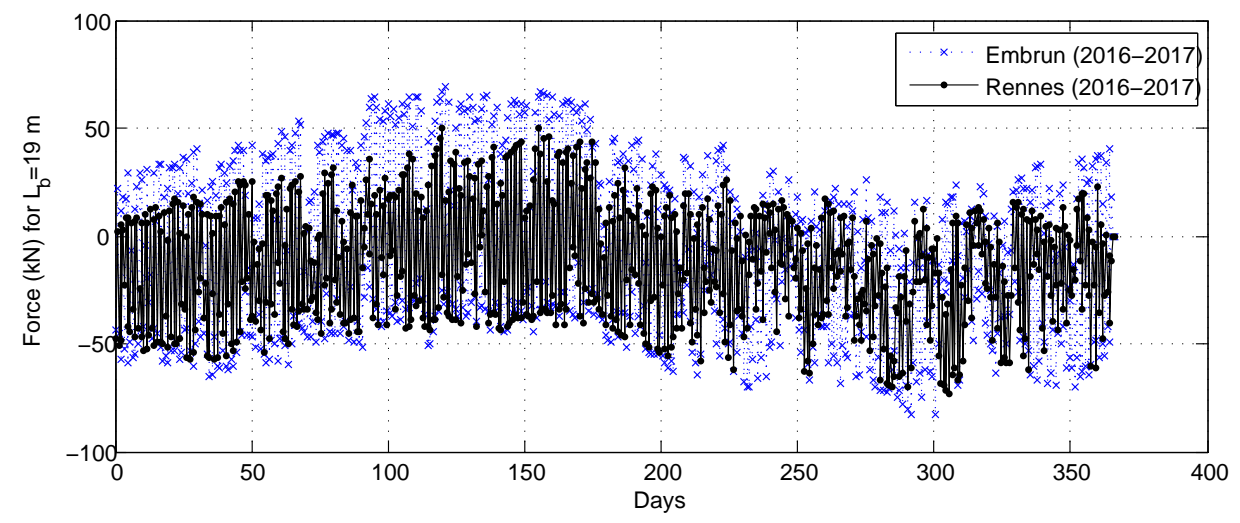

Figure 24: Force signal for $L_{b}=19 \mathrm{~m}$.

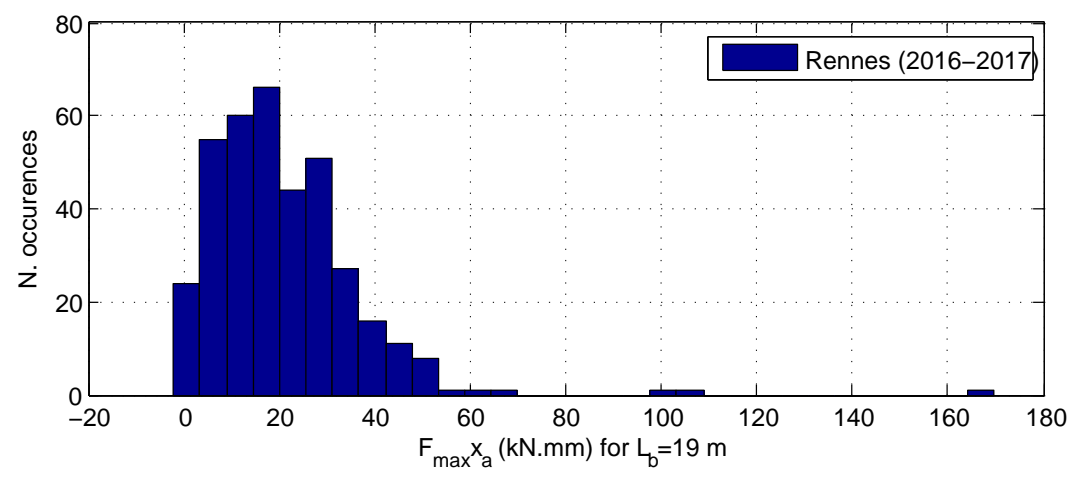

Figure 25: Histogram of $\Delta E_{f}^{\max }$.

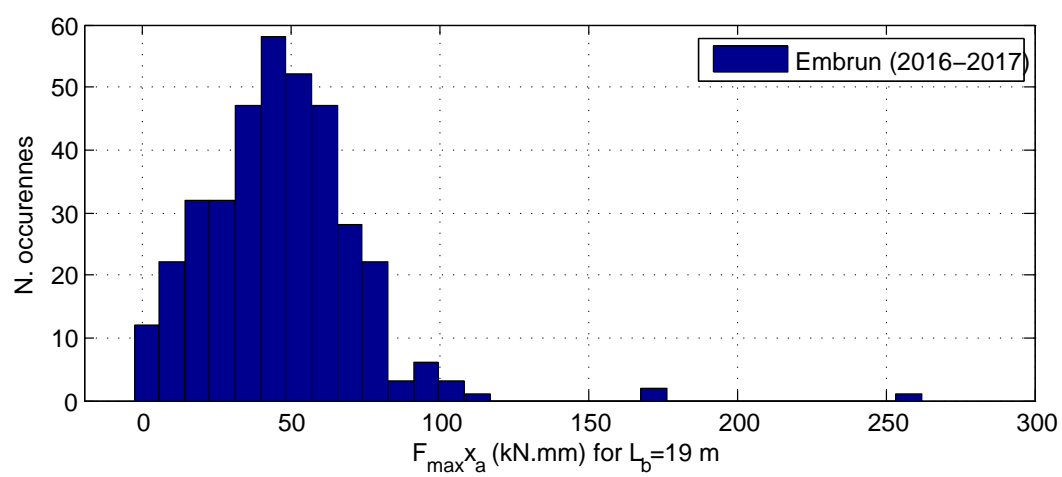

Figure 26: Histogram of $\Delta E_{f}^{\max }$.

The study is extended to 5 French cities representing different climates. Fig. 27 shows the evolution of the annual accumulated damage, still for a balcony length of $19 \mathrm{~m}$ and a safety factor $\gamma_{m}$ equal to 1 . It can be seen that the evolution of $D_{y}$ is very random. $D_{y}$ during the last 50 years at Rennes city, featuring an oceanic climate, is quasi constant compared to the one in Embrun, in the Alps, which is very fluctuating with a growing global trend. On the contrary, the damaging in 
Paris is rather decreasing. Bordeaux and Strasbourg give intermediate levels of damaging.

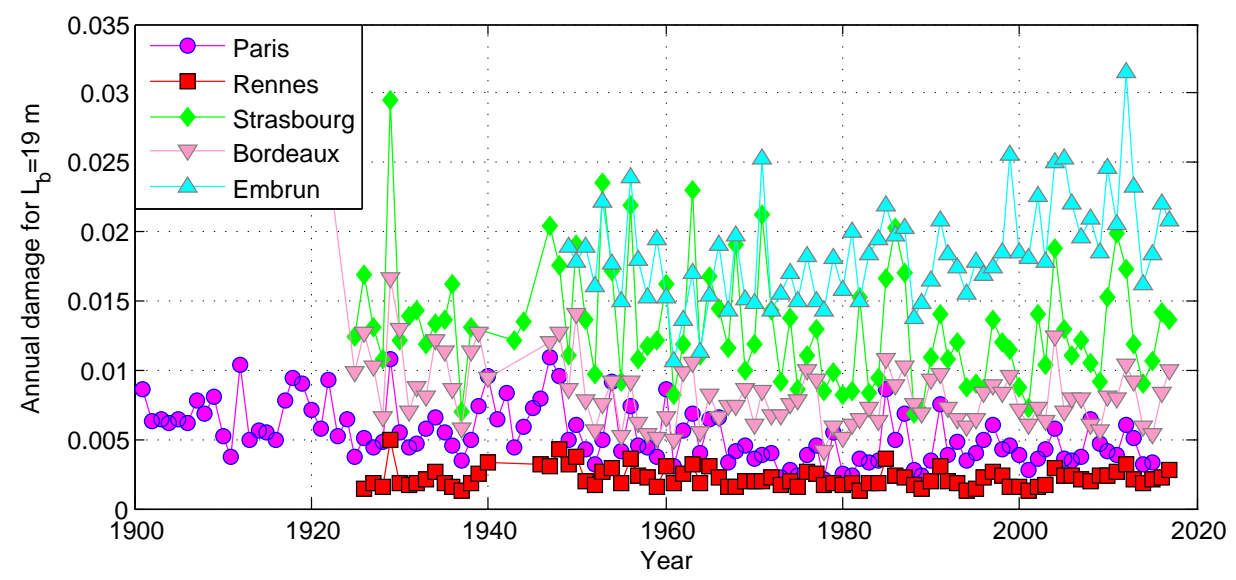

Figure 27: Evolution of $D_{y}$ for $L_{b}=19 m$.

\subsection{Computation of the distribution of annual damages based on historical recordings}

The evolution of the 50-year building life damage $D_{50, d}$ is calculated for the five different cities under consideration for a safety coefficient $\gamma_{m}$ equal to 1 . Its evolution in function of the balcony length is illustrated in Fig. 28. As could be expected, the life-time accumulated damage is larger in Embrun. Strasbourg, which is located in the east of France and is subject to a continental climate, gives also large damagings, while Rennes gives the lower ones. Bordeaux and Paris give intermediate values. These differences are consistent with the climatic zones defined in the Eurocodes. The evolution of the damaging with various values of the safety coefficient $\gamma_{m}$ is computed for different lengthes of balconies in the most unfavourable city, i. e. Embrun, as illustrated in Fig. 29. TBSSUNE can sustain fatigue load during the building service life for the balcony length up to 16.5 $\mathrm{m}, 18 \mathrm{~m}$ and $19 \mathrm{~m}\left(D_{50}=1\right)$ for a safety factor $\gamma_{m}=2,1.35$ and 1 , respectively. It appears that the safety factor does not substantially influence the balcony length. Because the balcony is, in general, made with a length smaller than $12 \mathrm{~m}$, the use of $\gamma_{m}=2$ already gives a large margin. Such large margin provides a proof that it is possible to develop stresses in a plastic range in SLS without a risk of collapse during the building service life. However, the reliability analysis in the safety format with larger database of the cities is needed to determine the actual value of the safety factor. 


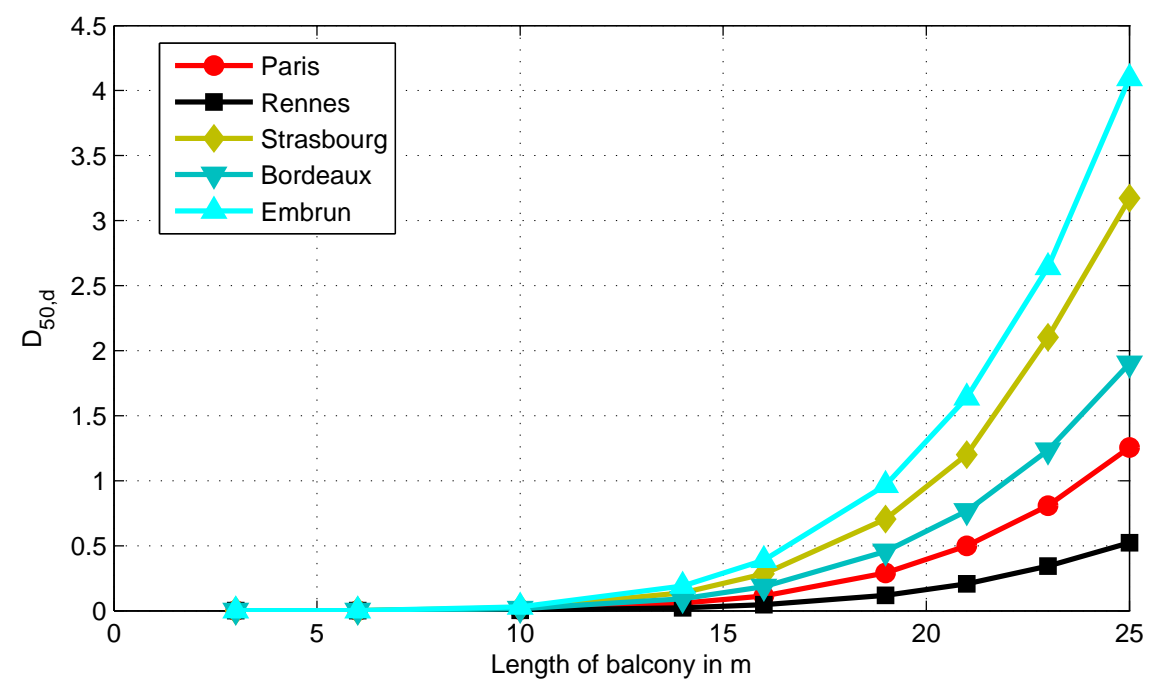

Figure 28: Evolution of $D_{50, d}$ in function of $L_{b}$ with $\gamma_{m}=1$

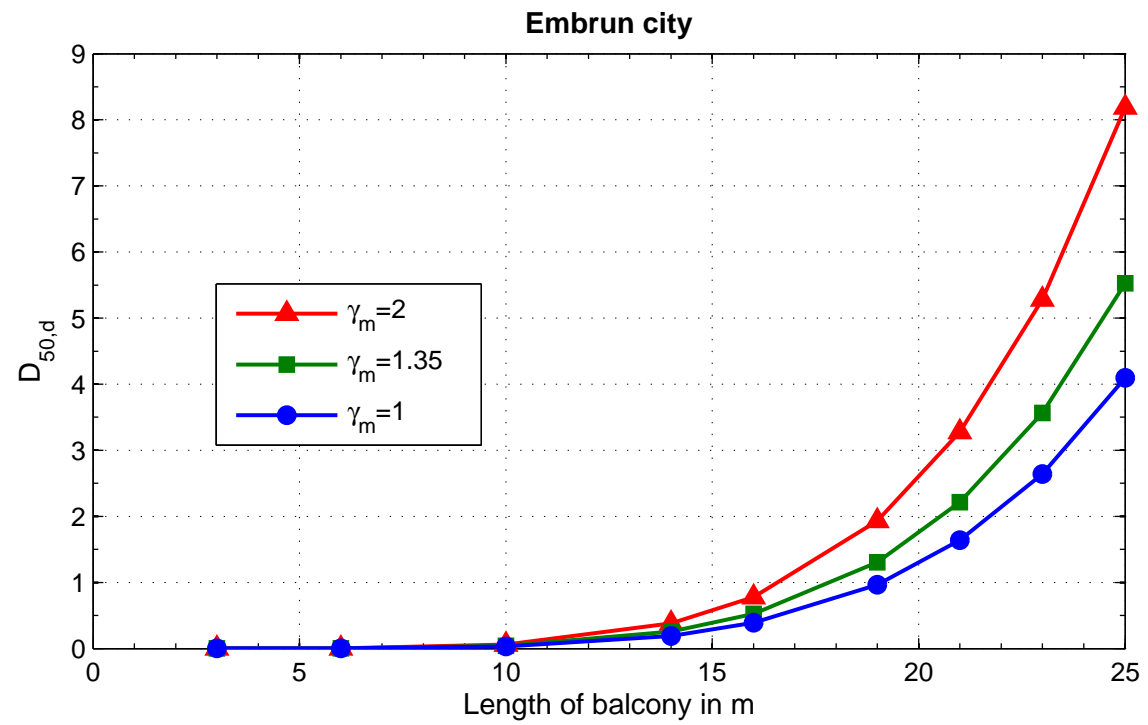

Figure 29: Evolution of $D_{50, d}$ in function of $L_{b}$ in Embrun city with different values of $\gamma_{m}$.

\section{Conclusions and perspectives}

The procedure for verifying the thermal break system SUNE against low-cycle fatigue loads induced by the deformations of the balcony due to the variations of the temperature has been presented in this paper. Primarily, eight cyclic experimental tests of the system are performed with several loading amplitudes. On one hand, they serve to define the fatigue design curve. On the other hand, they allow to develop a coupled plastic-damage mechanical model of the device. 
Then, the past temperature variations taken from ECA \& D database for five different cities are scaled in order to comply with the extreme values recommended in the Eurocodes. After adding the effect of the solar radiations, the elongation histories are computed for different lengthes of balconies. Force-displacement histories are deduced using the mechanical model, and the cycles applied to the system are counted by a rainflow algorithm. Finally, the fatigue design curve allows to verify the fatigue strength of the thermal break for the different configurations considered. The process is applied in five different cities for different lengths of balconies.

As could be expected, the annual accumulated damage is larger in mountainous regions than in tempered areas, and the evolution of the damage follows the same trends as the minimum and the maximum shade air temperatures defined in the French national annex of the Eurocode.

The design format and the related safety coefficients are not known at this stage. But, it is clear that a safe design can be achieved for usual lengths of balconies at least up to $12 \mathrm{~m}$. Moreover, a parametric study shows that the maximum length of the balcony is not proportional to the safety coefficient and that, even with a safety coefficient of 2 , a balcony length of $16 \mathrm{~m}$ can be reached in the most unfavourable location considered in the study.

This specific case illustrates that it is possible to exceed the conventional 0.2 percents yielding during service life without any risk for the integrity of the components. This offers a wide range of new possibilities, particularly in the case of shear keys used in thermal break systems.

Further investigations through reliability analysis are however needed in order to define an accurate safety format.

\section{Acknowledgements}

The authors gratefully acknowledge financial support by the ANR (Agence Nationale de la Recherche, France) through the project LabCom ANR B-HYBRID.

\section{Appendix A Cyclic force-displacement relationship}

\section{A.1 Yield function for TBS}

By taking into account the isotropic and kinematic hardening, the yield function for TBS-SUNE system is proposed as follow:

$$
f\left(F, F^{q}, R\right)=\left|F-F^{q}\right|-R
$$


where $F^{q}$ and $R$ are the thermodynamic force associated to the kinematic and isotropic hardening, respectively.

\section{A.2 Coupled plastic-damage model}

The following model is presented initially by Meschke et al. [12. It is herein presented for one dimensional case in which forces and displacements are considered as variables.

The following set of state variables is assumed for the thermodynamic state at any time t:

$$
\left\{x^{e}, x^{p}, x^{d}, p, q\right\}
$$

where $x$ is total displacement, $x^{p}$ plastic displacement, $x^{d}$ displacement associated to damage, $p$ the internal variable associated with the isotropic hardening and $q$ is the internal variable associated to the kinematic hardening. The choice of the internal variables is not unique. In fact, it is possible to substitute the displacement associated to damage by the plastic displacement. To do so, it is sufficient to observe that:

$$
F=k^{e} x^{e}=k^{d} x^{d}=k\left(x-x^{p}\right)
$$

in which $k^{e}$ is elastic moduli and $k^{d}$ is damage moduli that varies in function of the non-recoverable displacement. Following the above hypothesis, the total work done by the force $F$ is assumed to have the form:

$$
W=W\left(x^{e}, x^{p}, D^{d}, p, q\right)
$$

in which $D^{d}=1 / k^{d}$ is the damage compliance moduli. It is usual to assume that the total work can be split as

$$
W=W^{e}\left(x^{e}\right)+W^{d}\left(x^{d}, D^{d}\right)+W^{p}(p)+W^{q}(q)
$$

where

- $W^{e}\left(x^{e}\right)=\frac{1}{2} x^{e} k^{e} x^{e}$ is the work corresponding to the elastic displacement, see Fig. A1. and

- $W^{d}\left(x^{d}, D^{d}\right)=\frac{1}{2} x^{d} k^{d} x^{d}$ is the work corresponding to the displacement associated to damage which can be rewritten as $W^{d}\left(x^{d}, D^{d}\right)=\frac{1}{2} x^{d} k^{d} x^{d}=x^{d} k^{d} x^{d}-\frac{1}{2} x^{d} k^{d} x^{d}=F x^{d}-\frac{1}{2} D^{d} F^{2}$. 


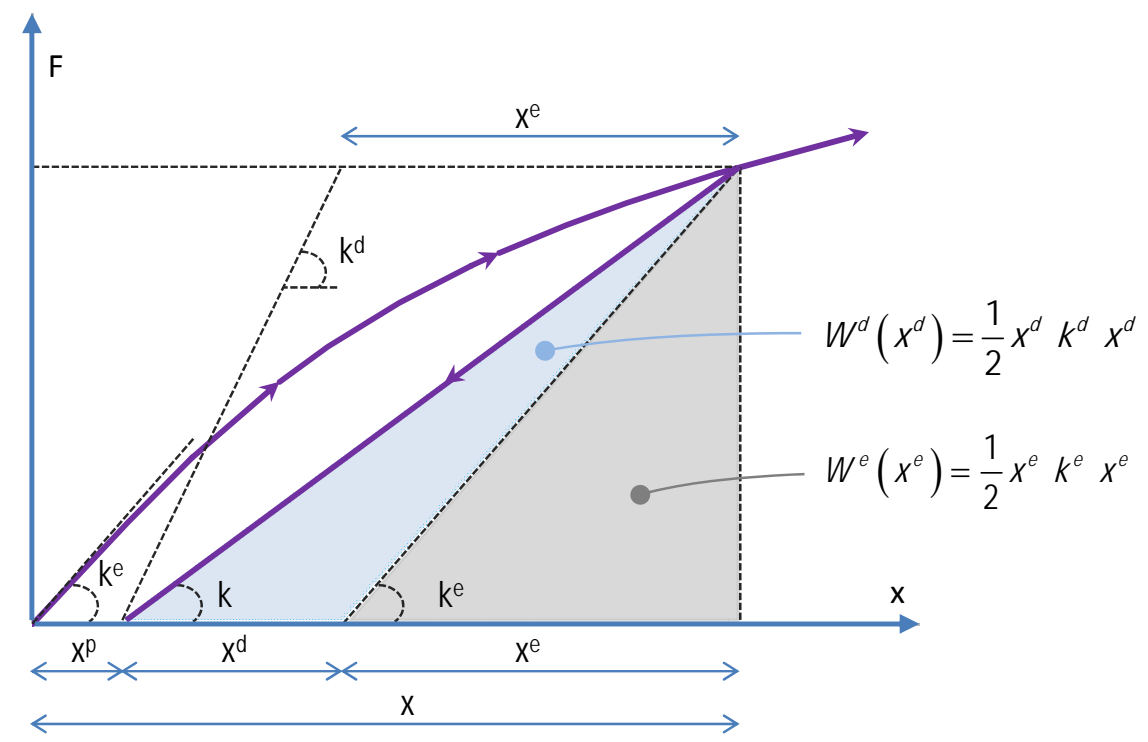

Figure A1: Elasto-plastic damage model.

Inserting the expressions of $W^{e}\left(x^{e}\right)$ and $W^{d}\left(x^{d}, D^{d}\right)$ in to Eq. A-5 and making use of Eq. A-3, we can rewrite the expression of the total work as follow:

$$
W=W^{e d}\left(x, x^{p}, D^{d}\right)+W^{p}(p)+W^{q}(q)
$$

where $W^{e d}\left(x, x^{p}, D^{d}\right)=\frac{1}{2}\left(D^{e}+D^{d}\right)^{-1}\left(x-x^{p}\right)^{2}=\frac{1}{2} D^{-1}\left(x-x^{p}\right)^{2}, D^{e}=1 / k^{e}$ and $D=1 / k$.

The Clausius-Duhem inequality requires

$$
0 \leq \dot{\mathfrak{D}}=F \dot{x}-\dot{W}
$$

Substituting Eq. (A-6) into Eq. (A-7), and making partial differential operation on each part of total work, one has:

$$
\dot{\mathfrak{D}}=\left(F-\frac{\partial W^{e d}}{\partial\left(x-x^{p}\right)}\right) \dot{x}+\frac{\partial W^{e d}}{\partial\left(x-x^{p}\right)} \dot{x}^{p}-\frac{\partial W^{e d}}{\partial D^{d}} \dot{D}^{d}-\frac{\partial W^{p}}{\partial p} \dot{p}-\frac{\partial W^{q}}{\partial q} \dot{q}
$$

Eq. (A-8) must be satisfied for all evolutions containing the elastic case without damage where $x^{p}=0, D^{d}=0, p=0$ and $q=0$; this implies the first elastic state law:

$$
F=\frac{\partial W^{e d}}{\partial\left(x-x^{p}\right)}=D^{-1}\left(x-x^{p}\right)
$$


From Eq. A-9), we define the following thermodynamic forces:

$$
\begin{aligned}
\hat{Y} & =\frac{\partial W^{e d}}{\partial D^{d}}=-\frac{1}{2} F^{2} \\
R(p) & =\frac{\partial W^{p}}{\partial p} \\
F^{q}(q) & =\frac{\partial W^{q}}{\partial q}
\end{aligned}
$$

The Clausius-Duhem inequality is then reduced to

$$
\dot{\mathfrak{D}}=F \dot{x}^{p}+\frac{1}{2} F^{2} \dot{D}^{d}-R(p) \dot{p}-F^{q}(q) \dot{q} \geq 0
$$

The interest here is to introduce a coupling between the two phenomena by introducing a single criterion that depends only on $F, R(p)$ and $F^{q}(q)$. In the absence of an explicit criterion on $\hat{Y}$, one can overcome its presence in the dissipation inequality. The area of convex reversibility $\mathbb{C}$ is defined in the space of thermodynamic forces $\left(F, F^{q}, R\right)$. It can be written as

$$
\mathbb{C}:=\left\{\left(F, F^{q}, R\right) \mid f\left(F, F^{q}, R\right) \leq 0\right\}
$$

where the yield surface $f\left(F, F^{q}, R\right)=0$ limits this area; inside which, no irreversibility is possible.

In analogy to classical plasticity theory, the evolution of the compliance moduli $D^{d}$, of the inelastic displacement $x^{p}$ and of the internal variables $(p, q)$ is obtained from exploiting the postulate of maximum dissipation [28].

$$
\inf _{\left(F, F^{q}, R\right)}[-\dot{\mathfrak{D}}]
$$

Thus, for a given set of variables in the admissible state $\left(F, F^{q}, R\right) \in \mathbb{C}$, the rates $\left(x^{p}, D^{d}, p\right.$ and $\left.q\right)$ are those that produce a stationary point of dissipation $\dot{\mathfrak{D}}$. To find the solution of this problem, the Lagrange multiplier method is used. The following Lagrangean function is introduced

$$
\begin{aligned}
\mathfrak{L}\left(F, F^{q}, R\right) & =-\dot{\mathfrak{D}}+\dot{\lambda} f\left(F, F^{q}, R\right) \\
& =F \dot{x}^{p}+\frac{1}{2} F^{2} \dot{D}^{d}-R(p) \dot{p}-F^{q}(q) \dot{q}+\dot{\lambda} f\left(F, F^{q}, R\right)
\end{aligned}
$$

where $\dot{\lambda} \geq 0$ is Lagrange multiplier. From the associated optimality conditions:

$$
\frac{\partial L}{\partial F}=0 ; \quad \frac{\partial L}{\partial F^{q}}=0 ; \quad \frac{\partial L}{\partial R}=0
$$


one gets:

$$
\begin{aligned}
\dot{x}^{p}+\dot{D}^{d} F & =\dot{\lambda} \frac{\partial f}{\partial F} \\
\dot{q} & =-\dot{\lambda} \frac{\partial f}{\partial F^{q}} \\
\dot{p} & =-\dot{\lambda} \frac{\partial f}{\partial R}
\end{aligned}
$$

Defining the differential displacement associated with the degradation of the compliance moduli by

$$
\dot{x}^{d a}=\dot{D}^{d} F
$$

and the inelastic displacement rate by

$$
\dot{x}^{p d}=\dot{x}^{p}+\dot{x}^{d a},
$$

one can rewrite Eq. A-19 in the form analogous to classical associative plasticity theory as

$$
\dot{x}^{p d}=\dot{\lambda} \frac{\partial f}{\partial F}
$$

It can be observed that the inelastic displacement rate $x^{p d}$ is composed of two parts: one part due to the plastic displacement and the other part due to the deterioration of the microstructure, resulting in an increase of the compliance moduli $D^{d}$. To separate these two parts, a scalar parameter $\beta$ is introduced [12]. The plastic and damage displacement is then given as

$$
\begin{array}{r}
\dot{x}^{p}=(1-\beta) \dot{\lambda} \frac{\partial f}{\partial F} \\
\dot{x}^{d a}=\dot{D}^{d} F=\beta \dot{\lambda} \frac{\partial f}{\partial F}
\end{array}
$$

Eq. A-26 results in the evolution law of the compliance moduli

$$
\dot{D}^{d}=\frac{\beta \dot{\lambda}}{F} \frac{\partial f}{\partial F} .
$$

The Lagrange multiplier is determined by the admissible state where the point corresponding to the loading state cannot quit the yield surface [28]. For a given yield function $f\left(F, F^{q}, R\right)$, we have Kuhn-Tucker loading/unloading and consistency conditions, respectively, as follow:

$$
\begin{array}{lrl}
\dot{\lambda} \geq 0, & f\left(F, F^{q}, R\right) \leq 0, & \dot{\lambda} f\left(F, F^{q}, R\right)=0 \\
\dot{\lambda}>0, & \dot{\lambda} \dot{f}\left(F, F^{q}, R\right)=0
\end{array}
$$


By evaluating the consistency condition Eq. $\mathrm{A}-29$ ) and making use of Eqs. $\mathrm{A}-9 \mathrm{~A}, \mathrm{~A}-20$ ) and $\mathrm{A}-21$ , one gets:

$$
\dot{f}\left(F, F^{q}, R\right)=\frac{\partial f}{\partial F} D^{-1} x-\dot{\lambda}\left[(1-\beta) \frac{\partial f}{\partial F} D^{-1} \frac{\partial f}{\partial F}+\frac{\partial f}{\partial F^{q}} \frac{\partial F^{q}}{\partial q} \frac{\partial f}{\partial F^{q}}+\frac{\partial f}{\partial R} \frac{\partial R}{\partial p} \frac{\partial f}{\partial R}\right] .
$$

Solving for the Lagrange multiplier $\dot{\lambda}$, one has:

$$
\dot{\lambda}=\frac{\frac{\partial f}{\partial F} D^{-1} x}{(1-\beta) \frac{\partial f}{\partial F} D^{-1} \frac{\partial f}{\partial F}+\frac{\partial f}{\partial F^{q}} \frac{\partial F^{q}}{\partial q} \frac{\partial f}{\partial F^{q}}+\frac{\partial f}{\partial R} \frac{\partial R}{\partial p} \frac{\partial f}{\partial R}}
$$

\section{A.2.1 Nonlinear isotropic hardening law}

The nonlinear isotropic hardening law can be determined by making use of the envelope curve obtained in Section 3.1. Differentiating the first elastic state law (Eq. (A-9)) with respect to time and making use of Eqs. A-22 and (A-23, one gets:

$$
\dot{x}=\frac{\dot{F}}{k^{e}}+D^{d} \dot{F}+\dot{x}^{p d} .
$$

To identify the hardening law, it is here assumed that the quantities $D^{d} \dot{F}$ is proportional to $x^{p d}$

$$
D^{d} \dot{F}=\zeta \dot{x}^{p d}
$$

where $\zeta$ is a constant scalar parameter. This parameter will be determined by adjusting the numerical result to the experimental ones in order to reproduce the finest unloading moduli.

Inserting Eq. (A-33) into Eq. (A-32), making use of Eqs. (A-1), (A-21) and (A-24) for positive forces, and performing time integration on the result, one obtains:

$$
x=\frac{F}{k^{e}}+(1+\zeta) p
$$

Substituting Eq. (A-34) into Eq. (1), inserting the result into Eq. (A-1) and ignoring the kinematic hardening part of the yield surface, one gets

$$
R(p)=k^{\prime}[(1+\zeta) p]^{n^{\prime}}
$$

\section{A.2.2 Linear kinematic hardening law}

In the present model, a linear kinematic hardening law is adopted, i.e.

$$
\frac{\partial F^{q}}{\partial q}=H
$$

where $H$ is the kinematic hardening moduli. 


\section{References}

[1] T. Keller, F. Riebel, A. Zhou, Multifunctional hybrid GFRP/steel joint for concrete slab structures, Journal of Composites for Construction 10 (6) (2006) 550-560.

[2] K. G. Wakili, H. Simmler, T. Frank, Experimental and numerical thermal analysis of a balcony board with integrated glass fibre reinforced polymer GFRP elements, Energy and Buildings 39 (1) (2007) 76-81.

[3] K. Goulouti, J. De Castro, T. Keller, Aramid/glass fiber-reinforced thermal break-thermal and structural performance, Composite Structures 136 (2016) 113-123.

[4] P. Keo, B. Le Gac, H. Somja, F. Palas, Experimental Study of the Behavior of a Steel-Concrete Hybrid Thermal Break System Under Vertical Actions, in: High Tech Concrete: Where Technology and Engineering Meet, Springer, 2573-2580, 2018.

[5] EN 1993-1-1, Eurocode 3: Design of steel structures: Part 1-1: General Rules and Rules for Buildings, European Committee for Standardization, 2005.

[6] EN 1990, Eurocode 0: Basis of structural design, European Committee for Standardization, 2002.

[7] NF A03-403-1990, Metal products. Low-cycle fatigue test. Produits malliques. Pratique des essais de fatigue oligocyclique, Association Francaise de Normalisation (AFNOR), 1990/12/1.

[8] ECCS, Recommended testing procedure for assessing the behaviour of structural steel elements under cyclic loads, 45, European Convention for Constructional Steelworks, Technical Committee1, TWG 1.3-Seismic Design, 1985.

[9] ATC, Guidelines for cyclic testing of components of steel structures, 24, Applied Technology Council, 1992.

[10] C. A. Castiglioni, H. P. Mouzakis, P. G. Carydis, Constant and variable amplitude cyclic behavior of welded steel beam-to-column connections, Journal of Earthquake Engineering 11 (6) (2007) 876-902.

[11] A. Plumier, R. Agatino, A. Castellani, C. Castiglioni, C. Chesi, Resistance of steel connections to low-cycle fatigue, in: XIth European Conference on Earthquake Engineering. Paris, 1998.

[12] G. Meschke, R. Lackner, H. Mang, An anisotropic elastoplastic-damage model for plain concrete, International Journal for Numerical Methods in Engineering 42 (4) (1998) 703-727.

[13] W. Ramberg, W. R. Osgood, Description of stress-strain curves by three parameters, Tech. Rep., National Advisory Committee for Aeronautics, 1943.

[14] O. Basquin, The exponential law of endurance tests, in: Proc Astm, vol. 10, 625-630, 1910.

[15] L. F. Coffin Jr, A study of the effects of cyclic thermal stresses on a ductile metal, trans. ASME 76 (1954) 931-950.

[16] S. S. Manson, Behavior of materials under conditions of thermal stress, Tech. Rep., National Advisory Committee for Aeronautics, 1954.

[17] S. Kandarpa, B. Spencer, D. Kirkner, Reliability analysis of structural components utilizing the strain-life method, Engineering Fracture Mechanics 53 (5) (1996) 761-774.

[18] J. Bannantine, Fundamentals of metal fatigue analysis, Prentice Hall, 1990.

[19] J. Morrow, Fatigue design handbook, Advances in Engineering 4 (3.2) (1968) 21-29.

[20] K. Smith, T. Topper, P. Watson, A stress-strain function for the fatigue of metals, Journal of Materials 5 (1970) 
$767-778$

[21] C. Boller, T. Seeger, Materials Data for Cyclic Loading: Part A to E, 42, Elsevier, 1987.

[22] H. Jahed, A. Varvani-Farahani, Upper and lower fatigue life limits model using energy-based fatigue properties, International Journal of Fatigue 28 (5) (2006) 467-473.

[23] EN 1993-1-9, Eurocode 3: Design of steel structures: Part 1-9: Fatigue, European Committee for Standardization, 2005.

[24] M. A. Miner, Cumulative damage in fatigue, Journal of Applied Mehanics 12 (3) (1945) A159-A164.

[25] A. Klein Tank, J. Wijngaard, G. Können, R. Böhm, G. Demarée, A. Gocheva, M. Mileta, S. Pashiardis, L. Hejkrlik, C. Kern-Hansen, et al., Daily dataset of 20th-century surface air temperature and precipitation series for the European Climate Assessment, International Journal of Climatology 22 (12) (2002) 1441-1453.

[26] EN 1991, Eurocode 1: Actions on structures: Part 1-5: General actions - Thermal actions, European Committee for Standardization, 2004.

[27] A. Niesłony, Determination of fragments of multiaxial service loading strongly influencing the fatigue of machine components, Mechanical Systems and Signal Processing 23 (8) (2009) 2712-2721.

[28] J. C. Simo, T. J. Hughes, Computational inelasticity, vol. 7, Springer Science \& Business Media, 2006. 